\title{
Effect of alloy composition on the oxidation-induced boron depletion in cast $\mathrm{Ni}$-base superalloy components
}

\author{
W. J. Nowak*, D. Naumenko, A. Jałowicka, D. J. Young, \\ V. Nischwitz and W. J. Quadakkers
}

The high temperature air oxidation of the two conventionally cast Ni-based superalloys Rene 80 containing 92 wt ppm boron and CM 247 containing $110 \mathrm{wt} \mathrm{ppm}$ of boron was studied at temperatures between 850 and $1050{ }^{\circ} \mathrm{C}$ and times ranging from 1 to $100 \mathrm{~h}$. Analysis by GD-OES and SEM/WDX/EBSD revealed the surface scale on Rene 80 after exposure at $1050{ }^{\circ} \mathrm{C}$ to consist of $\mathrm{Cr}_{2} \mathrm{O}_{3}$ with $\mathrm{TiO}_{2}$ in the outer part and $\mathrm{BCrO}_{3}$ and $\mathrm{CrTi}_{2} \mathrm{O}_{5}$ in the inner part. Internal $\mathrm{Al}_{2} \mathrm{O}_{3}$ precipitates were present below the external scale. After $1 \mathrm{~h}$ exposure of $\mathrm{CM} 247$ an inner dense alumina scale formed over eutectic alloy regions containing coarse $\gamma^{\prime}$ precipitates. Over dendritic regions a $\mathrm{Cr}$-rich oxide scale with $\mathrm{BCrO}_{3}$-precipitates formed initially and aluminum was internally oxidized. After longer oxidation times an alumina sub-scale grew from the internal precipitates, and oxidation of the initially present depleted alloy zones resulted in formation of outer $\mathrm{Ni}$ and $\mathrm{Co}$ rich oxides. In both alloys, boron depletion in the bulk alloy occurred due to formation of the mentioned boron rich oxide. The extent of depletion was substantially higher for the chromia forming Rene 80 than for $\mathrm{CM} 247$. In the latter material the boron depletion was suppressed after the formation of the dense, inner alumina scale.

\section{Introduction}

Ni-based superalloys [1-5] as well as martensitic steels [6] often contain minor additions of boron in the range of $20-200 \mathrm{wt} \mathrm{ppm}$ for increased alloy creep strength. Abe et al. [6] found boron incorporation into the grain-boundary $\mathrm{M}_{23} \mathrm{C}_{6}$ carbides in a martensitic 9\% $\mathrm{Cr}$ steel, which resulted in reduced carbide coarsening compared with the B-free version of this steel [6]. In a boron modified wrought Ni-based alloy 617, Tytko et al. [2] found boron enrichment mainly at the $\mathrm{M}_{23} \mathrm{C}_{6} / \mathrm{\gamma}$ and $\mathrm{M}_{23} \mathrm{C}_{6} / \mathrm{\gamma}^{\prime}$ interfaces. The authors suggested that the observed reduction

W. J. Nowak, D. Naumenko, A. Jałowicka, W.J. Quadakkers

Forschungszentrum Julich - IEK-2, Leo-Brandt-Straße, Julich 52428

(Germany)

E-mail: w.nowak@fz-juelich.de

D. J. Young

School of Materials Science and Engineering, University of New South Wales, Sydney, NSW 2052 (Australia)

V. Nischwitz

Forschungszentrum Julich, Central Institute for Engineering, Electronics, and Analytics, ZEA-3, Leo-Brandt-Straße, Julich 52428 (Germany) of $\mathrm{M}_{23} \mathrm{C}_{6}$ coarsening is caused by interfacial boron segregation rather than by boron incorporation into the carbide phase. In $y^{\prime}$ strengthened Ni-base alloys, addition of boron is claimed to result in boride formation at grain boundaries thus inhibiting grain boundary sliding [4].

Apart from its effect on the mechanical properties, boron addition has been found to affect high-temperature oxidation processes $[5,7,8]$. Based on statistical analysis related to oxidation rates measured for a number of Ni-based superalloys, Barrett et al. [7] claimed that minor boron additions promote formation of a non-protective NiO-based scale, thus suppressing the formation of more protective Cr- and Al-rich oxides. Khanna et al. [8] found that boron additions hampered protective alumina scale formation during oxidation of a NiCrAl model alloy.

It is well established that Ni-based superalloys containing boron are susceptible to deboronization, during high temperature heat-treatment [1]. However, very little is known about the exact mechanisms and kinetics of boron depletion. Exposure in oxidizing atmospheres at high temperature causes boron depletion which has been used to control the grain size in Nibased superalloys [9]. Deboronization has also been claimed to occur during annealing in hydrogen $[10,11]$. Chu et al. [11] reported boron depletion profiles in Ni-B model alloys after annealing in hydrogen between 900 and $1250^{\circ} \mathrm{C}$. 
Jalowicka et al. [5] recently reported formation of $\mathrm{BCrO}_{3}$ in the inner part of a chromia scale that formed during $1050{ }^{\circ} \mathrm{C}$ air oxidation of the cast Ni-base superalloy Rene 80 . Formation of the mixed $\mathrm{B} / \mathrm{Cr}$ oxide resulted in fast boron depletion from the alloy. This was attributed to the high thermodynamic stability of boron containing oxides in combination with rapid interstitial diffusion of boron in the alloy matrix $[5,12]$.

In order to improve creep strength, Ni-base superalloy compositions have been modified considerably over the years. In particular, the Cr-content has been decreased and the Al-content increased. Moreover, Ta and Hf have been added at the expense of Ti. These alloy modifications were aimed at increasing the mole fraction of the strengthening $\gamma^{\prime}$-phase without formation of brittle TCP phases. The modifications resulted in a substantial change in oxidation behavior compared with earlier generations of conventionally cast Ni-base superalloys. An example of such a low $\mathrm{Cr} /$ high $\mathrm{Al}$ alloy is CM 247. For optimized creep properties, the alloy contains approximately $100 \mathrm{wt}$ ppm boron. During the transient stages of oxidation, the alloy is reported to form an oxide scale consisting of $\mathrm{NiO}$ and $\mathrm{Cr}_{2} \mathrm{O}_{3}$, as well as Ti- and Tacontaining oxides [13]. After longer exposure times, an $\mathrm{Al}_{2} \mathrm{O}_{3}$ rich sub-scale forms below the transient oxides. Similar oxide scale compositions were observed by Niewolak et al. [14].

Considering the different oxide scale composition and microstructure of CM 247 compared to Rene 80, a different mechanism of boron oxidation and boron depletion rate in the alloy may be expected. In the present work a detailed analysis of the oxidation products on the two mentioned alloys using a number of surface analytical techniques is presented. The corresponding boron depletion kinetics are then independently measured and correlated with the oxide scale compositions.

\section{Experimental}

The chemical compositions of the bulk alloys Rene 80 and CM 247 were analyzed by inductively coupled plasma optical emission spectroscopy (ICP-OES) and mass spectrometry (ICP-MS) for B and Zr (Table 1). The C, N, S, O contents were analyzed using infrared analysis (Table 2).

Rectangular coupons with dimensions of $20 \times 10 \times 2 \mathrm{~mm}$ were cut from the as-received ingots, ground to a 1200 -grit surface finish and ultrasonically cleaned in ethanol prior to exposure. The specimens were isothermally oxidized in laboratory air at 850,950 , and $1050{ }^{\circ} \mathrm{C}$ for times of $1,5,20,50$, and $100 \mathrm{~h}$ using electrically heated tube furnaces with a heating rate of $10 \mathrm{~K} / \mathrm{min}$ and a cooling rate of $2 \mathrm{~K} / \mathrm{min}$. Two specimens were exposed for each test condition; in each case, one specimen was used for

Table 1. Chemical compositions (in wt\%) of studied Ni-based superalloys as determined by ICP-OES

Elements in wt\%

\begin{tabular}{lcccccccccc}
\cline { 2 - 9 } Alloy & $\mathrm{Cr}$ & $\mathrm{Ta}$ & $\mathrm{Co}$ & $\mathrm{Mo}$ & $\mathrm{W}$ & $\mathrm{Al}$ & $\mathrm{Ti}$ & $\mathrm{Zr}$ & $\mathrm{B}$ & $\mathrm{Hf}$ \\
\hline Rene 80 & 14.0 & - & 9.4 & 4.1 & 4.3 & 2.9 & 5.0 & 0.010 & 0.009 & - \\
CM 247 & 8.2 & 3.4 & 9.4 & 0.5 & 9.8 & 5.4 & 0.7 & 0.010 & 0.010 & 1.3 \\
\hline
\end{tabular}

Table 2. Concentrations (in wt\%) of the elements $\mathrm{C}, \mathrm{N}, \mathrm{O}$, and $\mathrm{S}$ of the $\mathrm{Ni}$-base superalloys in Table 1 as determined by infrared analysis

Elements in wt\%

\begin{tabular}{lcccc}
\cline { 2 - 5 } Alloy & $\mathrm{C}$ & $\mathrm{N}$ & $\mathrm{O}$ & $\mathrm{S}$ \\
\hline Rene 80 & 0.160 & $<0.001$ & $<0.001$ & $<0.001$ \\
CM 247 & 0.063 & $<0.001$ & $<0.001$ & $<0.001$ \\
\hline
\end{tabular}

characterization of the oxidation product and one for bulk boron analysis (see below). Additionally, thermogravimetric analyses (TGA 92-16.18 SETARAM ${ }^{\circledR}$ ) at $1050^{\circ} \mathrm{C}$ for $50 \mathrm{~h}$ exposure were carried out in synthetic air in a thermobalance with a heating rate of $90 \mathrm{~K} / \mathrm{min}$ and a cooling rate of $10 \mathrm{~K} / \mathrm{min}$.

The oxidized specimens were analyzed by glow discharge optical emission spectroscopy (GD-OES). Analysis of the radiation obtained from a crater sputtered through the scale (with a diameter of $4 \mathrm{~mm}$ ) yields concentrations of all elements present as a function of sputtering time. The GD-OES depth profiles were quantified using the procedure described in Ref. [15]. Additionally, the oxidation products were examined in metallographic cross-sections. Before cross-sectioning, the samples were sputtered with a thin layer of gold and subsequently a Ni-coating was deposited electrochemically from a Ni-sulphate bath to protect the oxide scales from damage during metallographic preparation. Metallographic cross-sections were then prepared by standard grinding and polishing procedures and analysed using optical microscopy, scanning electron microscopy (SEM) combined with energy dispersive Xray spectroscopy (EDX), wavelength dispersive X-ray spectroscopy (WDX) and electron backscatter diffraction (EBSD).

For measuring the bulk boron concentration in the oxidized, $2 \mathrm{~mm}$ thick coupons, the oxide scale was removed from the specimens by grinding, and subsequently the oxide-free alloy was investigated by ICP-MS.

\section{Results}

\subsection{Characterization of materials in the as-received condition}

Figures 1-4 show the alloy microstructures in the as-received condition. Alloy Rene 80 shows grains of approximately $500 \mu \mathrm{m}$, consisting of $\mathrm{\gamma}^{\prime}-\mathrm{Ni}_{3} \mathrm{Al}$ precipitates in a $\mathrm{\gamma}-\mathrm{Ni}$ matrix. In contrast, CM 247 shows a dendritic microstructure (Fig. 1b). In the dendritic regions a $\mathrm{\gamma} / \mathrm{\gamma}^{\prime}$ morphology similar to that in Rene 80 was found; coarse eutectic $\gamma^{\prime}$-precipitates are present in the interdendritic regions (Fig. 2b) $[1,16]$. Both alloy microstructures feature the presence of carbide precipitates. Rene 80 formed $\mathrm{Ti} /$ $\mathrm{Mo} / \mathrm{W}$ containing carbides (Fig. 3), which were present within the grains and some preferential precipitation at the grainboundaries was found (Fig. 2a). CM 247 formed Ti/W/Ta/Hfcontaining primary carbide precipitates (Fig. 4) that accumulated mainly at the grain boundaries and/or in the interdendritic (eutectic) regions. Hf is mainly present in the primary carbides as well as in the $\gamma^{\prime}$ precipitates. 

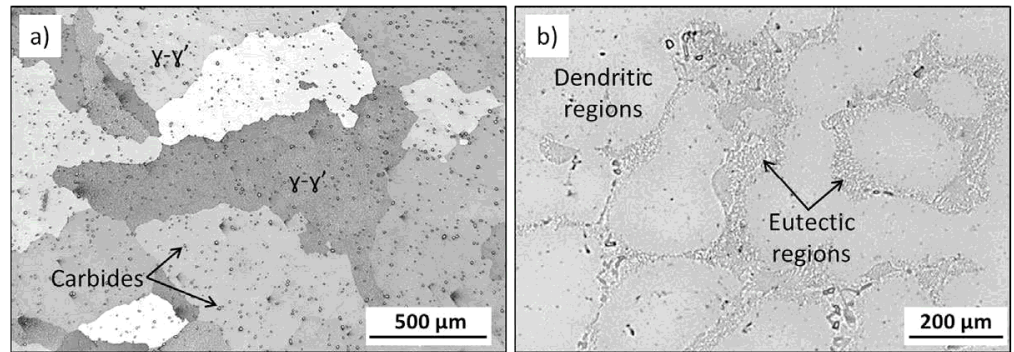

Figure 1. Light optical images showing metallographic cross-sections of Rene 80 (a) and $\mathrm{CM} 247$ (b) in the as-received condition

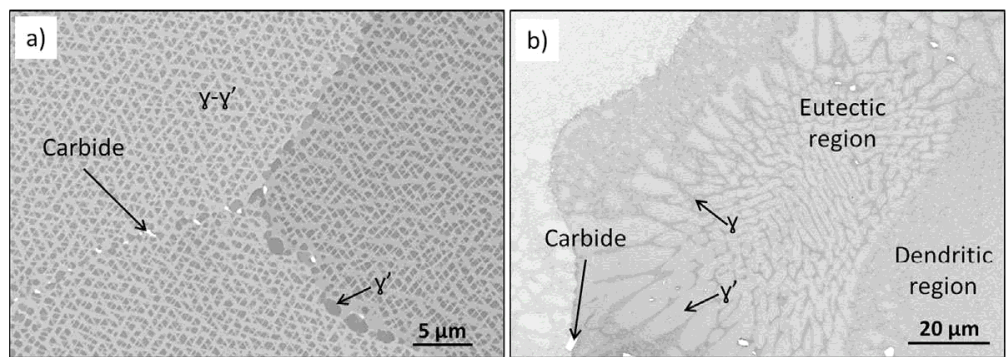

Figure 2. SEM backscattered electron images showing cross-sections of a) Rene 80 and b) $\mathrm{CM} 247$ in the as received condition
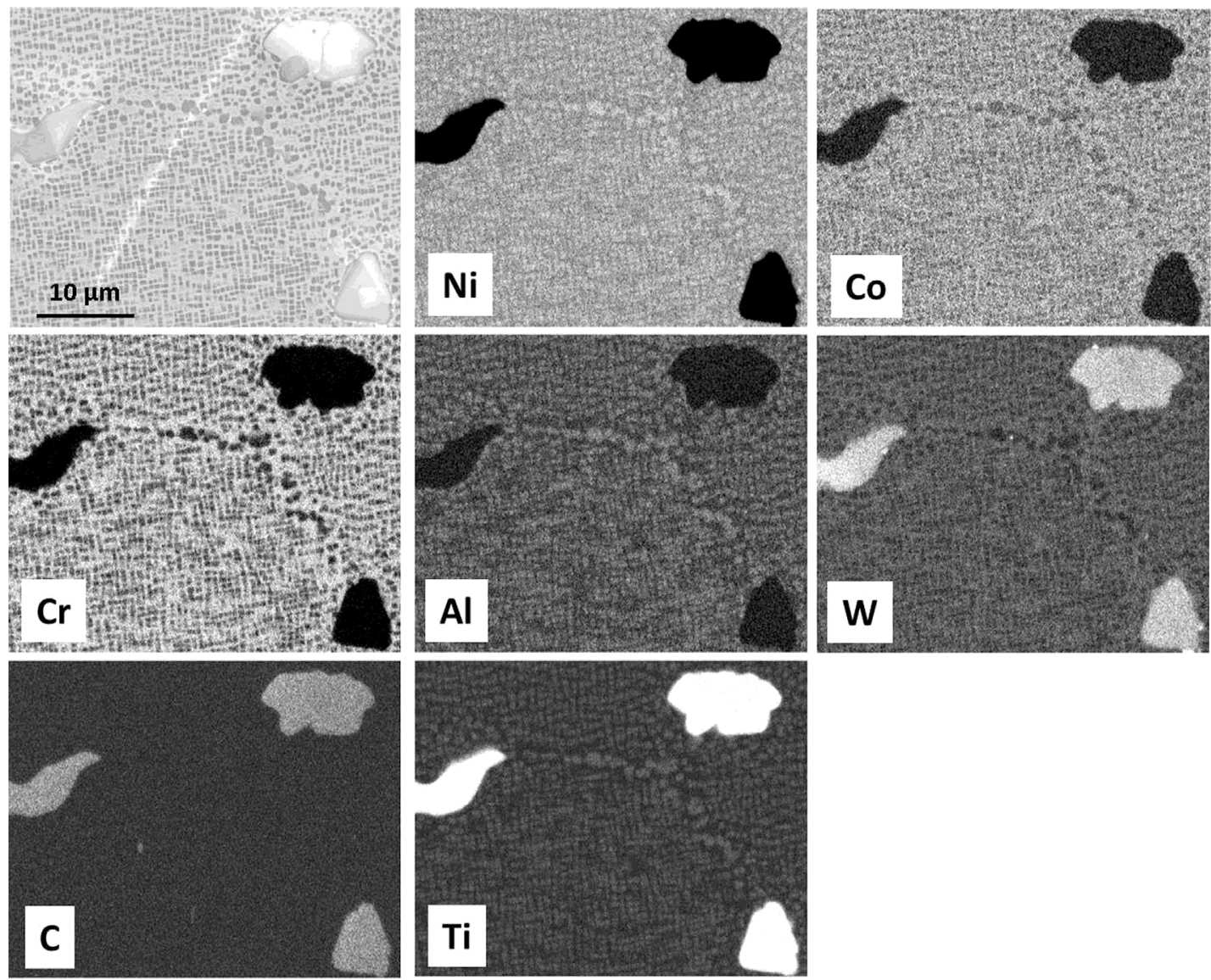

Figure 3. SEM back scattered electron image (upper left) and corresponding EDX elemental maps for cross-section of Rene 80 in the as-received condition 

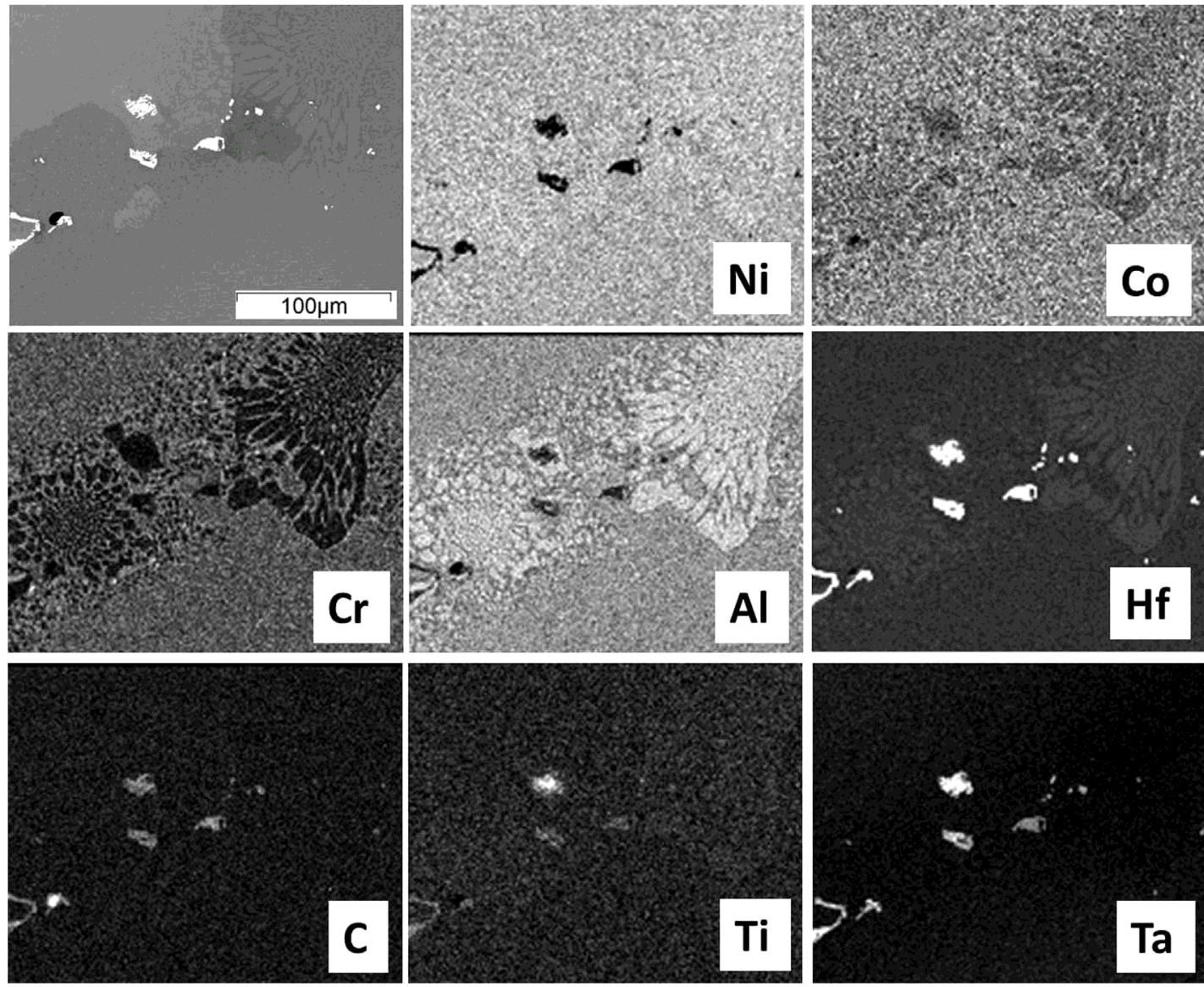

Figure 4. SEM back scattered electron image (upper left) and corresponding EDX elemental maps for cross-section of CM 247 in the as-received condition

\subsection{Oxidation kinetics}

Figure 5a shows mass changes measured continuously for Rene 80 and CM 247 during isothermal exposure (TGA analyses) at $1050^{\circ} \mathrm{C}$ in synthetic air up to $50 \mathrm{~h}$. CM 247 shows a relatively low mass gain (about $0.5 \mathrm{mg} \cdot \mathrm{cm}^{-2}$ ) after $50 \mathrm{~h}$ of exposure, in which the major mass gain was obtained during the early stages of exposure. The instantaneous apparent parabolic oxidation rate constant $\mathrm{k}_{\mathrm{w}}^{\prime}[17,18]$ (Fig. 5b) shows a drop of more than one order of magnitude in the first $10 \mathrm{~h}$ of exposure. The $\mathrm{k}_{\mathrm{w}}^{\prime}$-value then slowly decreases with time,
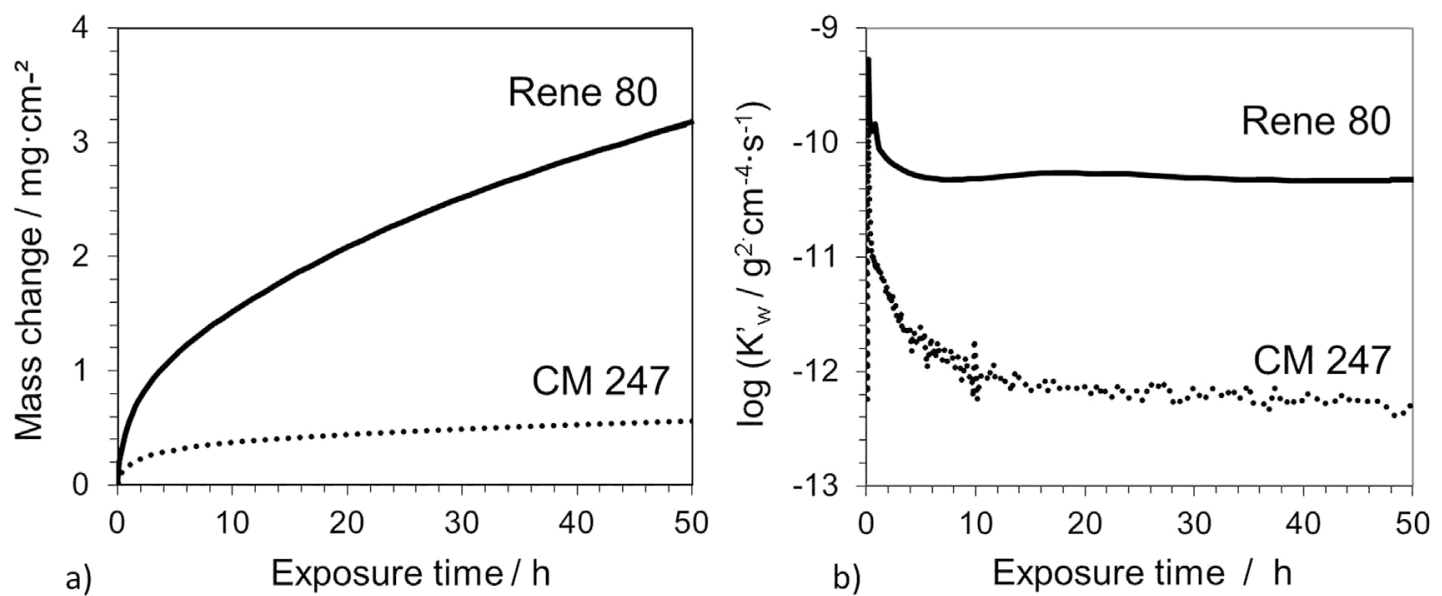

Figure 5. Thermogravimetric test results obtained for Rene 80 and $\mathrm{CM} 247$ during isothermal exposure at $1050{ }^{\circ} \mathrm{C}$ in synthetic air for $50 \mathrm{~h}$ : a) mass change as function of time and b) instantaneous, apparent parabolic rate constant $\mathrm{k}_{\mathrm{w}}{ }_{\mathrm{w}}$ calculated using data in a) according to procedure described in Ref. [18] 
reaching about $5.5 \cdot 10^{-13} \mathrm{~g}^{2} \cdot \mathrm{cm}^{-4} \cdot \mathrm{s}^{-1}$ at the end of the test. Rene 80 shows a substantially higher mass gain than CM 247. The measured instantaneous value of $\mathrm{k}_{\mathrm{w}}^{\prime}$ obtained for Rene 80 initially decreases and quickly reaches a constant value of around $4.7 \cdot 10^{-11} \mathrm{~g}^{2} \cdot \mathrm{cm}^{-4} \cdot \mathrm{s}^{-1}$ after only about $5 \mathrm{~h}$. In this time period it is approximately two orders of magnitude higher than that for CM 247.

\subsection{Characterization of oxide scale on Rene 80}

In Refs. $[5,19]$ the oxide scale formation as function of time during air oxidation of Rene 80 at $1050^{\circ} \mathrm{C}$ was presented. Selected results (after $20 \mathrm{~h}$ exposure at $1050^{\circ} \mathrm{C}$ in synthetic air) will be presented here for easier readability of the text.

Figure 6 shows the GD-OES profile obtained for Rene 80 after exposure at $1050{ }^{\circ} \mathrm{C}$ in synthetic air for $20 \mathrm{~h}$. A substantial enrichment of $\mathrm{Ti}$ in the outer part of the oxide scale is apparent (Fig. 6a). This suggests formation of an outer $\mathrm{TiO}_{2}$ layer on top of a scale mainly consisting of chromia. The outer scale additionally shows a slight enrichment of $\mathrm{Ni}$ and more markedly Co. A maximum in the Ti profile is observed in the inner part of the chromia scale, and at a slightly greater depth, another maximum in boron (Fig. 6b). A shallow relative maximum is found in the scale and internal oxidation of aluminum is indicated by the correlated peaks in the $\mathrm{Al}$ and $\mathrm{O}$ profiles in the sub-scale regions.

The SEM cross-sectional images of Rene 80 confirmed formation of an oxide scale consisting of an outer $\mathrm{TiO}_{2}$ layer below which a $\mathrm{Cr}$-rich oxide scale formed. Beneath the scale-alloy
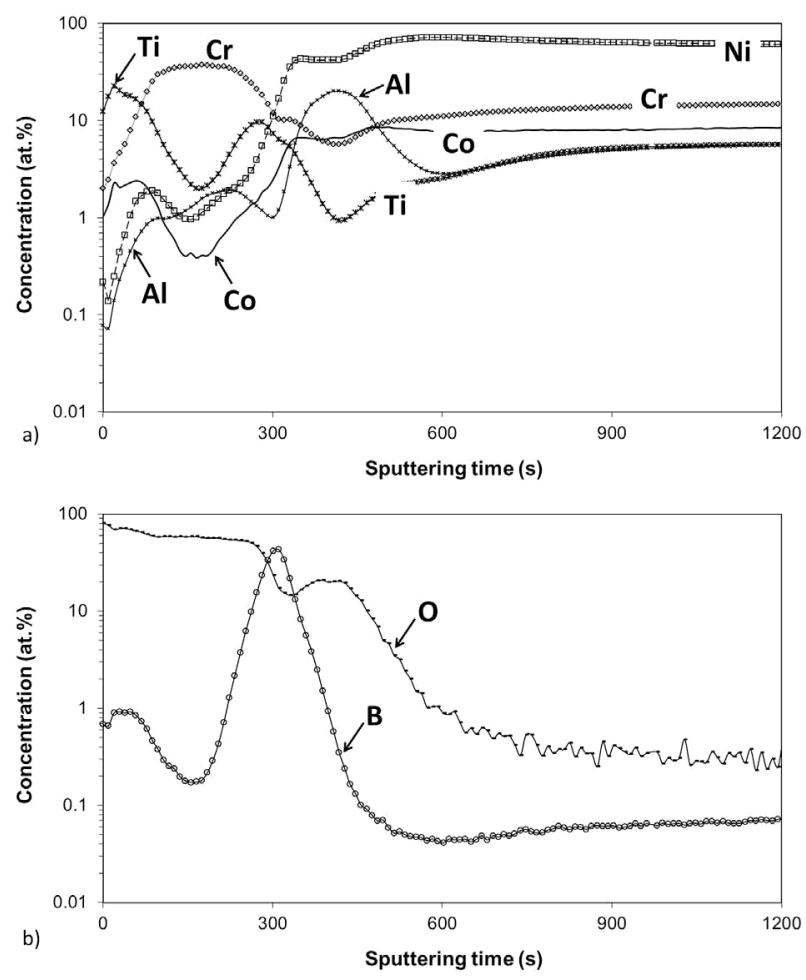

Figure 6. GD-OES depth profiles of Rene 80 after oxidation at $1050^{\circ} \mathrm{C}$ in synthetic air for $20 \mathrm{~h}$ showing depth profiles of: a) metallic elements and b) selected non-metallic elements [5] interface, $\mathrm{Al}_{2} \mathrm{O}_{3}$ is present in the form of internal oxide precipitates, below which TiN precipitates are visible (Fig. 7). These observations are in agreement with the GD-OES data in Fig. 6. In the inner part of the oxide scale, formation of a boron rich and a titanium rich oxide could be detected by SEM/WDX. This finding is also in good agreement with the GD-OES depth profile (compare Figs. 6 and 7). EBSD-analysis (Fig. 8) combined with WDX performed in the inner part of the oxide scale revealed the presence of what is inferred to be $\mathrm{BCrO}_{3}$ and $\mathrm{CrTi}_{2} \mathrm{O}_{5}$.

\subsection{Oxide scale composition on CM 247}

The GD-OES depth profile of CM 247 after $1 \mathrm{~h}$ of exposure at $1050{ }^{\circ} \mathrm{C}$ in synthetic air (Fig. 9) shows enrichment of $\mathrm{Ni}$ in the very outer part of the oxide scale, while the main part of the scale consists of Cr-rich oxide. Boron is found in the outer, and especially in the inner region of the chromium-rich scale. The latter is related to formation of a mixed $\mathrm{B} / \mathrm{Cr}$ oxide, as will be illustrated below. In contrast with Rene 80 , a further relative enrichment of B is seen which seems to be correlated with the enrichment of Al in the internal oxidation zone. In between these two inner peaks in boron concentration, co-enrichment of Ti and Ta can be observed.

The SEM backscattered electron image of the surface of CM 247 (Fig. 10a and b) oxidized for $1 \mathrm{~h}$ at $1050{ }^{\circ} \mathrm{C}$ shows that the results of the GD-OES profiles (which relate to a sputter crater with a diameter of approximately $4 \mathrm{~mm}$ ) should be interpreted with some care. The alloy formed a laterally inhomogeneous oxide scale, in which the oxide formed on the dendritic regions differs from that formed on the eutectic regions (compare Figs. $1 \mathrm{~b}$ and 4 ). The scale formed on the latter regions (in the following designated as "Zone I") was relatively thin and consisted mainly of outer Ni/Al-rich oxide and an inner thin alumina scale (Fig. 11a). In the dendritic regions (in the following designated as "Zone II") a thicker scale was present which consisted in the outer side mainly of Cr-rich oxide (Figs. 10b and 11b) and a relatively wide zone in which Al was internally oxidized.

In spite of the lateral inhomogeneity of the oxide scales, the GD-OES gives at least qualitative information, e.g., related to boron incorporation in the oxidation process. Due to the high

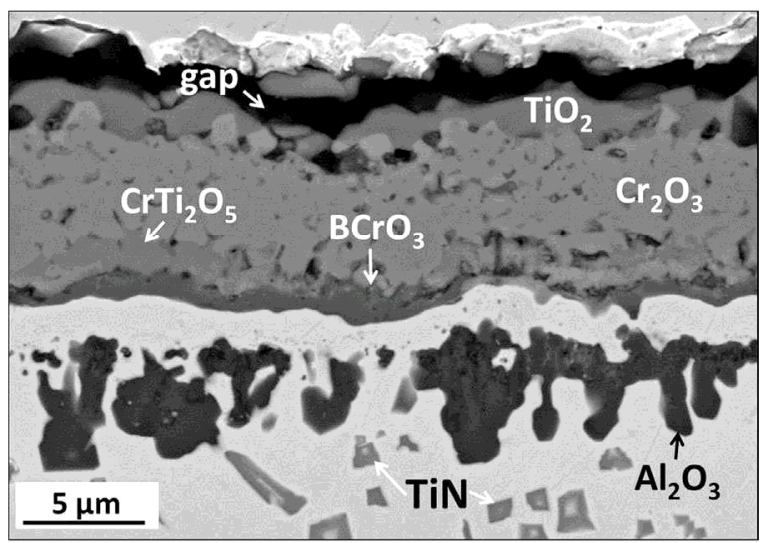

Figure 7. SEM/BSE image of cross sectioned Rene 80 after exposure at $1050{ }^{\circ} \mathrm{C}$ in synthetic air for $20 \mathrm{~h}$ [5] 


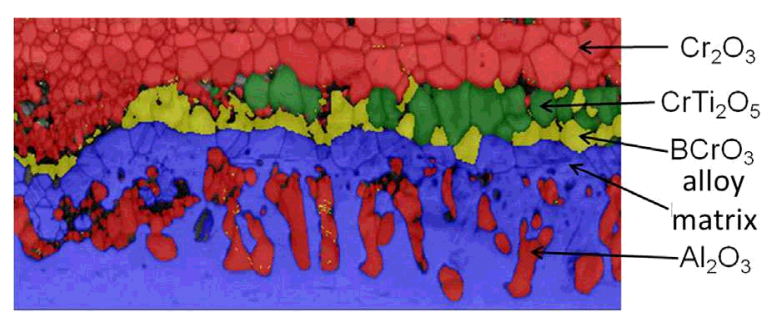

$10 \mu \mathrm{m}$

Figure 8. EBSD map of the phases near the interface between alloy and oxide scale on Rene 80 after $20 \mathrm{~h}$ exposure at $1050^{\circ} \mathrm{C}$ in synthetic air

sensitivity of GD-OES for boron, enrichment of this element can easily be detected, which is substantially more difficult using other analysis methods.

In the oxide scale formed in Zone I no indication of boron incorporation after $1 \mathrm{~h}$ oxidation could be found in metallographic cross sections by EDX/WDX. In Zone II however, $\mathrm{BCrO}_{3}$ was found to be locally present in the inner part of the chromia scale (Fig.12), with a microstructure similar to that observed for Rene 80 (Fig. 8). The bright contrast zone between the outer chromia scale and the internal oxidation zone is in fact twophase. It consists of Al- and Cr-depleted alloy matrix and slightly lighter appearing precipitates of a mixed Ti/Ta-oxide containing some Cr (Fig. 12). The morphology of the depleted alloy matrix intrusions into the chromia scale is very likely related to the
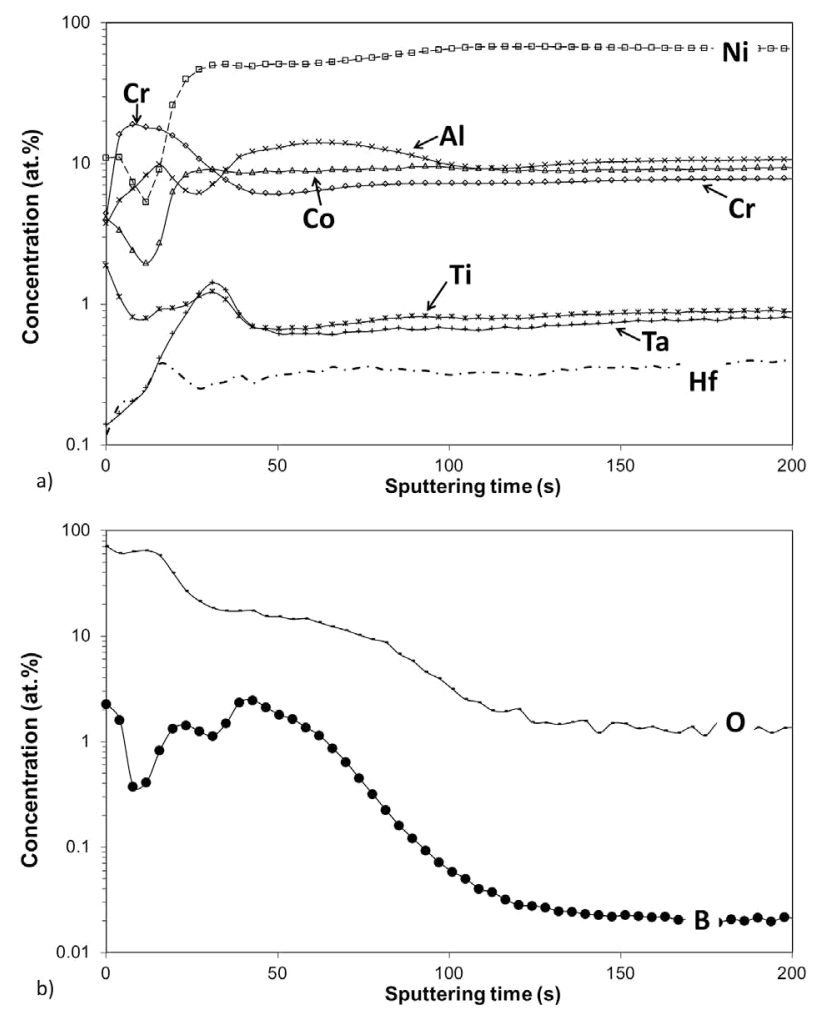

Figure 9. CD-OES depth profiles of CM 247 after oxidation at $1050^{\circ} \mathrm{C}$ in laboratory air for $\mathrm{ih}$ showing depth profiles of: a) metallic elements and b) selected non-metallic elements volume change imparted by the internal oxidation of Al. The latter results, as has frequently been described (see e.g. [20]), in generation of compressive stresses in the alloy matrix which leads to outward movement of metal.

The GD-OES depth profile of CM 247 exposed for $5 \mathrm{~h}$ revealed a higher overall enrichment of $\mathrm{Ni}$ in the outer part of the scale compared to the $1 \mathrm{~h}$ oxidation experiment. Below the Nirich oxide a Cr-rich zone is apparent. Enrichment of boron is observed in the inner part of the Cr-rich oxide scale. In spite of the limitations in interpretation of the GD-OES profiles due to the lateral inhomogeneity of the oxide, the results indicate the overall enrichment of boron in the oxidized regions to be more substantial than observed for the specimen exposed for $1 \mathrm{~h}$ (compare Figs. 13 and 9). As with the observations after $1 \mathrm{~h}$ exposure, a tail of boron enrichment, though at much lower concentrations, is present at larger depths. This second region of enrichment seems to be correlated with the zone of internal oxidation of Al. In addition, co-enrichment of $\mathrm{Ti} / \mathrm{Ta}$ is visible beneath the outer boron peak location (Fig. 13).

Figure 14 shows the formation of a very thin multi-layered oxide scale, with $\mathrm{NiO}$ and $\mathrm{Ni}$-Al-spinel in the outer part and $\mathrm{Al}_{2} \mathrm{O}_{3}$ in the inner part of the scale formed in Zone I after $5 \mathrm{~h}$ exposure. The inner alumina scale contained substantial amounts of Hfoxide pegs. No indications of boron containing phases were found, and the amount of mixed $\mathrm{Ti} / \mathrm{Ta}$-oxide precipitates was very small.

SEM cross-sections of the scale formed in Zone II after $5 \mathrm{~h}$ of exposure at $1050{ }^{\circ} \mathrm{C}$ (Fig. 15) showed an external chromia base scale and internal oxide precipitates similar to those found after $1 \mathrm{~h}$ oxidation (Fig. 11b). However, locally a thin, continuous alumina layer started to form (see right part of Fig. 15). This is accompanied by a change in morphology of the bright contrast, two-phase zone located between chromia layer and internal oxidation region; additionally, $\mathrm{NiO}$ is formed in contact with the gas. Figure 16 shows WDX/EDX elemental mappings of oxidation products in Zone II after $5 \mathrm{~h}$ exposure at $1050^{\circ} \mathrm{C}$. The image contains a boundary between two alumina product morphologies. In the right part of the figure, internal alumina precipitates like those found after $1 \mathrm{~h}$ oxidation are retained, whereas a dense alumina layer has developed at the reaction front visible in the left part of the figure. It is apparent from Fig. 16 that in the region in which a continuous alumina scale has started to form, Ni/Co-rich oxide has formed in the outer part of the oxide scale. Below this layer, mixed $\mathrm{Co} / \mathrm{Cr} / \mathrm{Ni}$ oxides can be observed. Thus, the initially present chromia scale (Fig. 11b) has been transformed into a mixed oxide containing mainly $\mathrm{Co}, \mathrm{Cr}$, and $\mathrm{Ni}$. The zone containing $\mathrm{Cr} / \mathrm{Al}$ depleted metal matrix found after shorter oxidation time (Fig. 9) has started to oxidize, whereas the $\mathrm{Ta} / \mathrm{Ti}$ rich oxides remain. The phase $\mathrm{BCrO}_{3}$ is present only in the regions in which a continuous inner $\mathrm{Al}_{2} \mathrm{O}_{3}$ layer has not yet formed (right side of Fig. 16).

After $50 \mathrm{~h}$ exposure, the growth of a continuous inner alumina scale is observed not only in Zone I but also in Zone II (Fig. 17). However, local variations in the scale morphology originating from the local differences in alloy microstructure can still be seen (Fig. 17).

Figure 18 shows the oxide scale morphology after $100 \mathrm{~h}$ exposure of CM 247 at $1050{ }^{\circ} \mathrm{C}$ (Zone II). The outer scale consists 

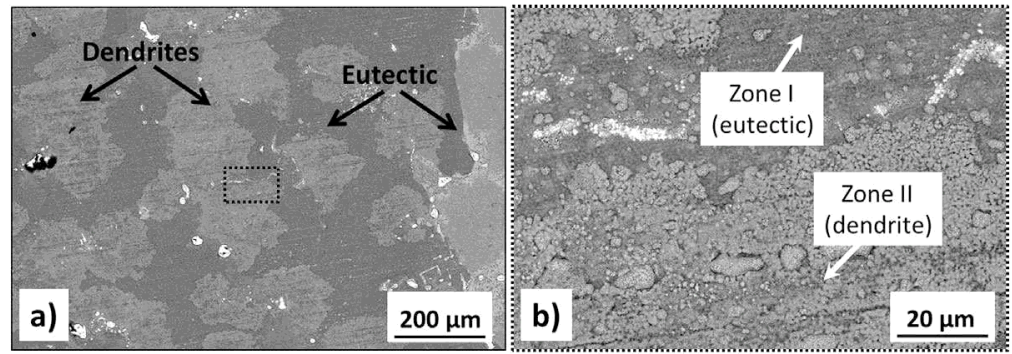

Figure 10. SEM image showing the surface of CM 247 after exposure at $1050^{\circ} \mathrm{C}$ in laboratory air for $1 \mathrm{~h}$ revealing different types of oxide scale formed over dendritic and eutectic regions.: a) overview and b) detailed view of boxed area in a)

of a heterogeneous mixture containing $\mathrm{NiO}, \mathrm{Cr}_{2} \mathrm{O}_{3}$, and mixed $\mathrm{Ni} / \mathrm{Co} / \mathrm{Cr}$ oxides. The inner scale mainly consisted of alumina, containing bright contrast precipitates. From X-ray mappings (not shown here) these oxide precipitates were found to be rich in Ti near the interface with the outer scale and rich in Ta, $\mathrm{Zr}$, and $\mathrm{W}$ near the interface with the alloy. Near the interface with the outer oxide layer, dark-appearing regions were present (Fig. 19). WDX analyses revealed these areas to contain boron. The X-ray mappings showed that hardly any boron containing regions were present near the interface of the alumina-rich inner scale with the alloy (Fig. 19).

Quantitative SEM/WDX point analysis of the mixed boron rich precipitates (Fig. 19) gave an approximate composition of 30Al-10B-60O (at\%). Attempts to identify the crystal structure of the Al/B oxide precipitates using EBSD were unsuccessful. In the literature, several mixed Al/B-oxides are
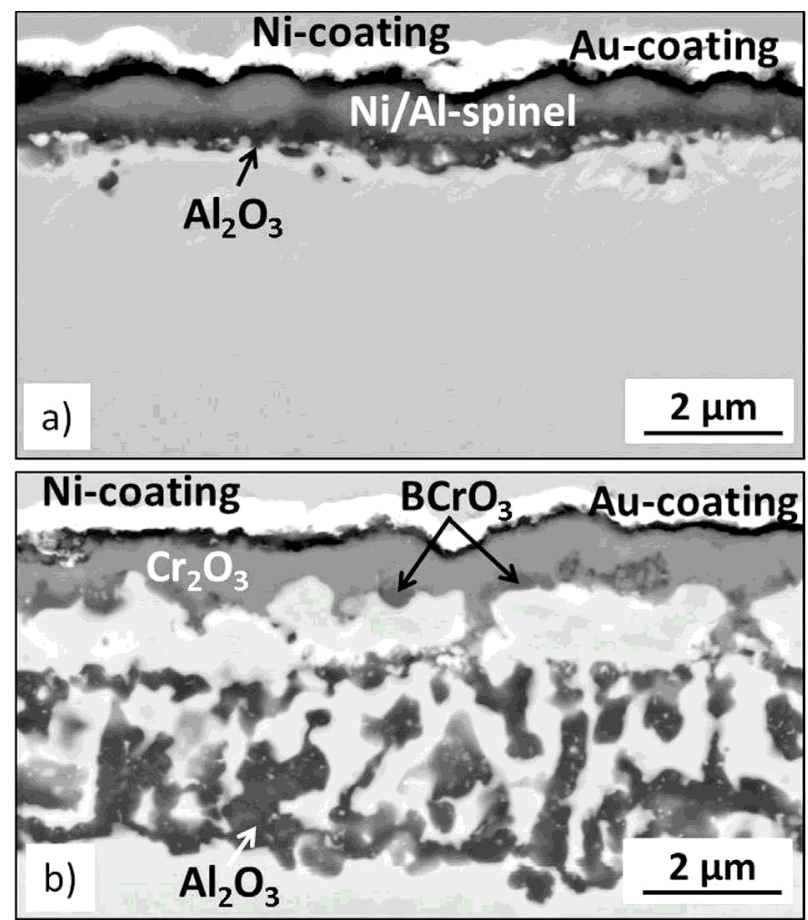

Figure 11. SEM images of cross sectioned CM 247 after $1 \mathrm{~h}$ of exposure at $1050{ }^{\circ} \mathrm{C}$ in laboratory air showing formation of a) thin spinel with alumina sub-scale (Zone I in Fig. 10) and b) Cr-rich oxide scale with internal $\mathrm{Al}_{2} \mathrm{O}_{3}$ precipitates (Zone II in Fig. 10) reported with a stoichiometry close to that measured by WDX in the present work. These include $\mathrm{Al}_{3} \mathrm{BO}_{6}$ reported by Capponi et al. [21], $\mathrm{Al}_{5} \mathrm{BO}_{9}$ [22,23], and $\mathrm{Al}_{18} \mathrm{~B}_{4} \mathrm{O}_{33}$ by Scholze et al. [24]. Fisch et al. [22] proposed that the latter compound exhibits a varying $\mathrm{B} / \mathrm{O}$ ratio and should be designated as $\mathrm{Al}_{5-x} \mathrm{~B}_{1+x} \mathrm{O}_{9}$ with $0.021<\mathrm{x}<0.038$. Based on the quantitative WDX analysis in the present work, the $\mathrm{Al} / \mathrm{B}-$ mixed oxide precipitates may be $\mathrm{Al}_{3} \mathrm{BO}_{6}$ or $\mathrm{Al}_{18} \mathrm{~B}_{4} \mathrm{O}_{33}$. However, further studies are necessary to unequivocally identify the crystal structure of the Al/B-rich oxide precipitates.

\section{Oxidation-induced boron depletion}

The boron concentration remaining in the bulk alloy was measured by ICP-MS after the oxide scale had been removed by grinding, as described in the Experimental section. As shown in Ref. [5] the formation of $\mathrm{BCrO}_{3}$ in the oxide scale (Fig. 7) on Rene 80 after oxidation at $1050{ }^{\circ} \mathrm{C}$ resulted in rapid B-depletion (Fig. 20). After $20 \mathrm{~h}$ of exposure at $1050{ }^{\circ} \mathrm{C}$ in laboratory air about $90 \%$ of the boron was depleted from the $2 \mathrm{~mm}$ thick sample of Rene 80 . Figure 20 illustrates that in the $2 \mathrm{~mm}$ thick coupons of CM 247 the depletion of the boron reservoir measured is about $30 \%$ after $20 \mathrm{~h}$ exposure and $50 \%$ after $100 \mathrm{~h}$ exposure at $1050{ }^{\circ} \mathrm{C}$. Apparently CM 247 is less prone to boron depletion than Rene 80 . The measurement of the boron content in both studied alloys revealed that also after oxidation at lower oxidation temperatures boron is depleted, although the extent of depletion is far less than at $1050{ }^{\circ} \mathrm{C}$ (Fig. 21). At all temperatures studied, boron depletion was less pronounced in CM 247 than in Rene 80.

\section{Discussion}

\subsection{Oxide scale composition}

Considering solely their $\mathrm{Cr}$ and $\mathrm{Al}$ contents, both studied superalloys Rene 80 and CM 247 might be expected to form alumina scales, according to the oxidation map for ternary $\mathrm{Ni}-\mathrm{Cr}-\mathrm{Al}$ alloys published by Giggins and Pettit [25] (Fig. 22). This is indeed observed in the case of CM247 after about 20h; although, differences in behavior were found locally, corresponding to differences in alloy microstructure. However, Rene 80 forms an external chromia-based scale accompanied by internal Al-oxidation, even after much longer exposure times [26]. 

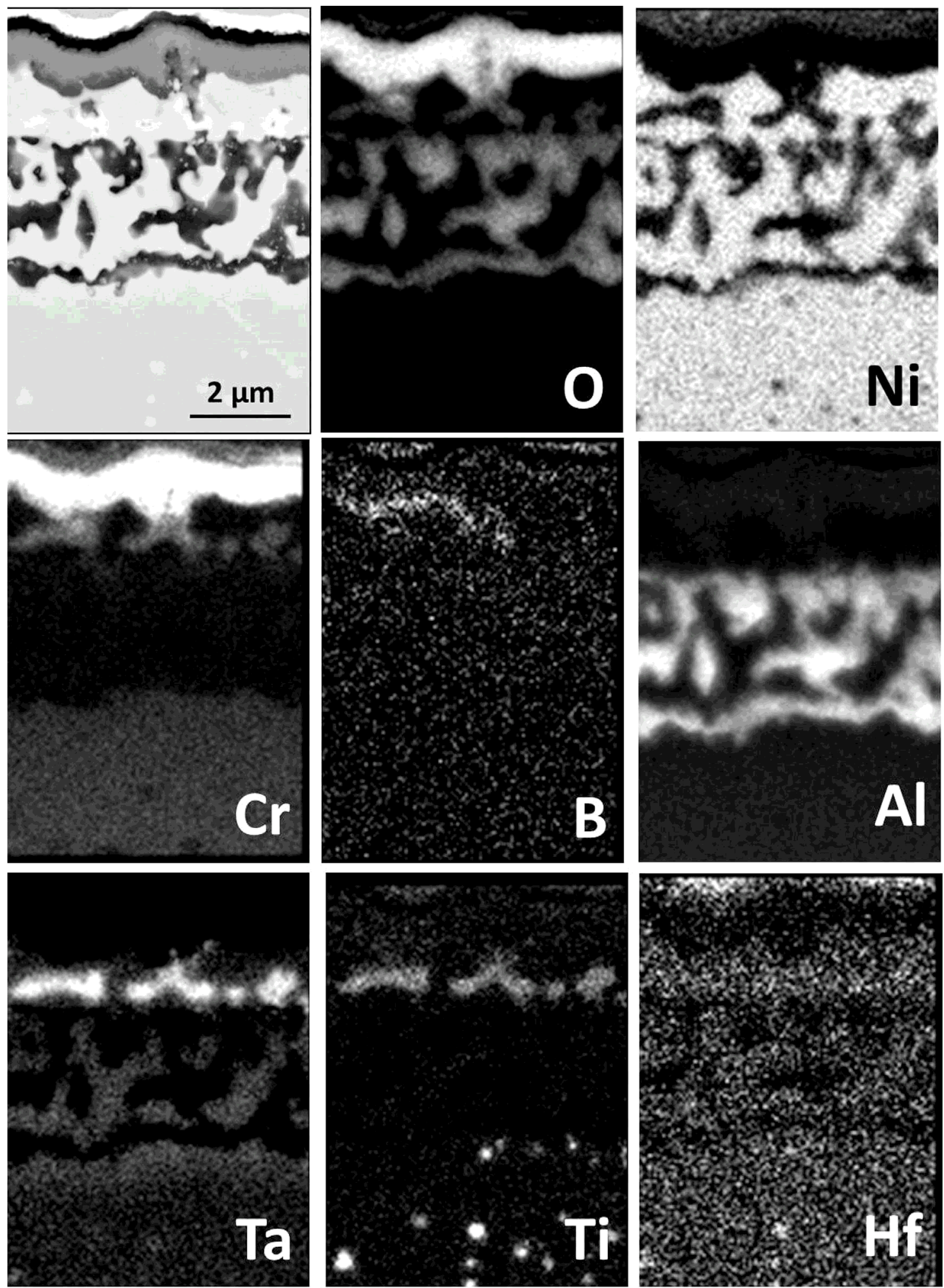

Figure 12. SEM back scattered electron image and corresponding EDX (WDX for B) elemental maps for cross-section of CM 247 exposed for $1 \mathrm{~h}$ at $1050^{\circ} \mathrm{C}$ in laboratory air (Zone II in Fig. 10) (compare Fig. 11b) 

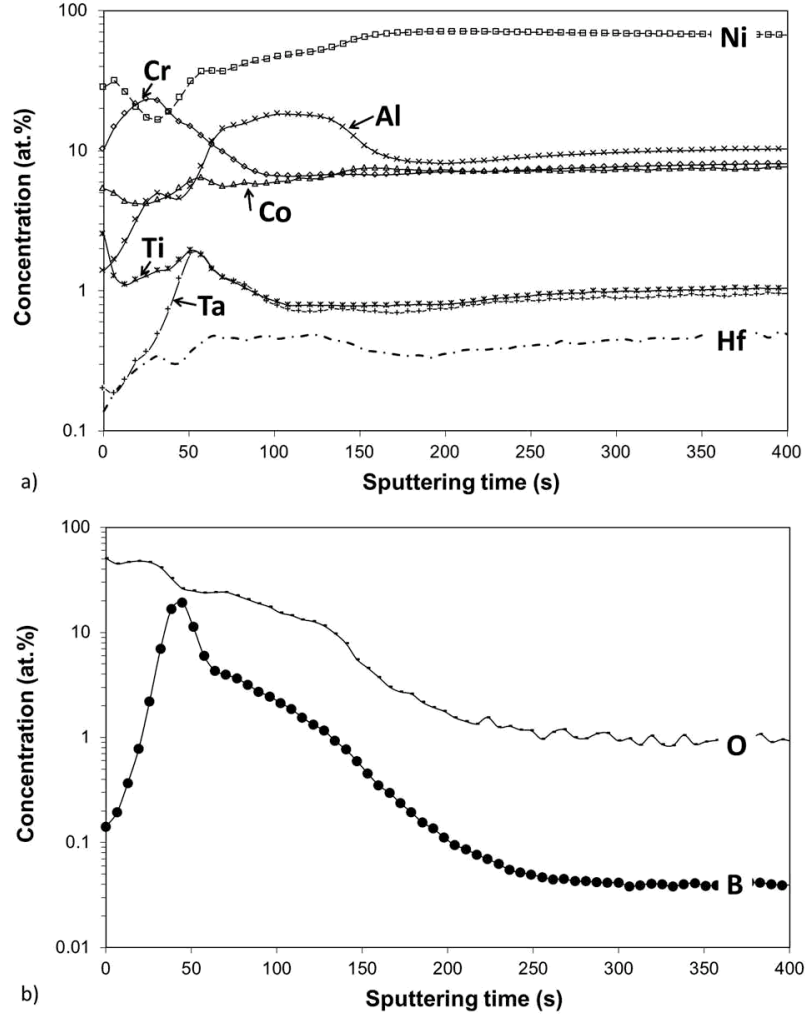

Figure 13. GD-OES depth profiles of CM 247 after oxidation at $1050^{\circ} \mathrm{C}$ in laboratory air for $5 \mathrm{~h}$ showing depth profiles of: a) metallic elements and b) selected non-metallic elements

The oxidation map in Fig. 22 was constructed for oxidation of ternary $\mathrm{Ni}-\mathrm{Cr}-\mathrm{Al}$ alloys and consequently does not take into account the effect of the various alloying elements on the oxidation of the studied alloys. The chromia scale growth rate on Rene 80 was found to be increased by the high alloy Ti-content due to p-type doping of chromia by $\mathrm{Ti}$ [26]. The high growth rate of the external chromia-base scale was shown to hamper formation of an alumina sub-scale [26]. The characteristic

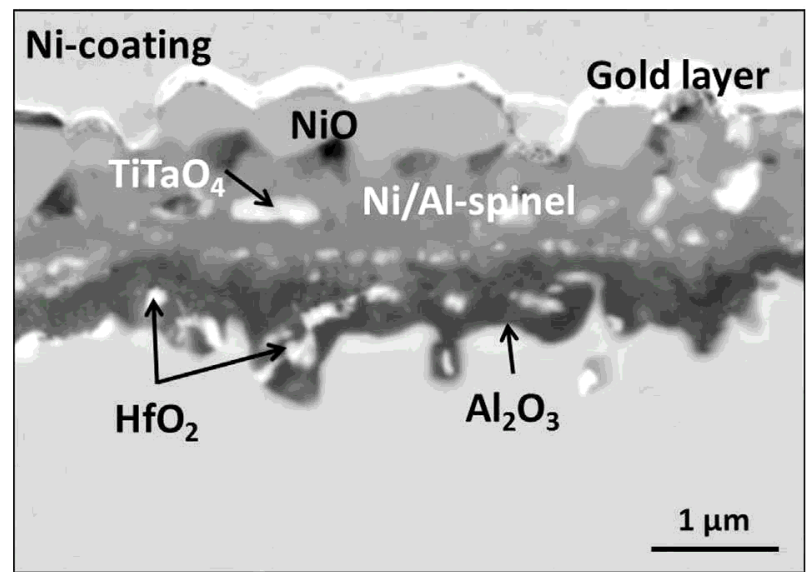

Figure 14. SEM image of the cross section of CM 247 exposed at $1050^{\circ} \mathrm{C}$ in laboratory air for $5 \mathrm{~h}$ showing oxide scale formed in Zone I

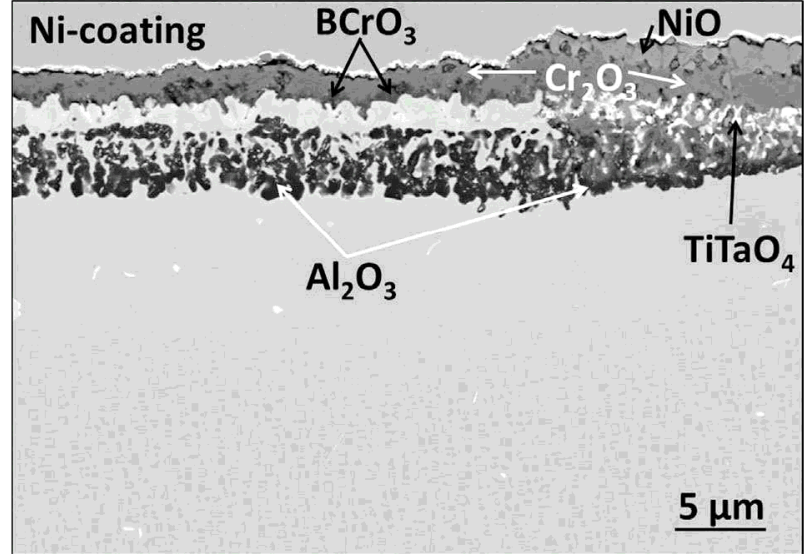

Figure 15. SEM image of cross-section in Zone II of CM 247 after $5 \mathrm{~h}$ exposure at $1050^{\circ} \mathrm{C}$ in laboratory air showing (in right side of the figure) local transformation from internal to external oxidation

external chromia rich scale and the internal oxidation of $\mathrm{Al}$ were observed for Rene 80 after all studied exposure times at $1050{ }^{\circ} \mathrm{C}$ starting from $1 \mathrm{~h}$ exposure $[5,19,26]$. This is in agreement with the plot of the apparent instantaneous parabolic rate constant, $\mathrm{k}_{\mathrm{w}}^{\prime}(\mathrm{t})$ (Figure 5) showing a more or less constant value between approximately $5 \mathrm{~h}$ and the maximum exposure time of $50 \mathrm{~h}$. Apparently, no fundamental change in oxidation mechanism occurs in this time period.

Unlike the case of Rene 80, the oxide scale formed on CM 247 is laterally inhomogeneous (Fig. 10). This originates from the microstructure of CM 247, which is laterally inhomogeneous (Fig. 1) featuring dendrites (Zone I, Fig. 10), primary Hf, Ta rich carbides and eutectic regions with coarse $\mathrm{y}^{\prime}$ precipitates (Zone II (Figs. $2 \mathrm{~b}$ and 10). This resulted after $1 \mathrm{~h}$ oxidation at $1050{ }^{\circ} \mathrm{C}$ in the oxide scale morphology varying significantly with the microstructure of the underlying alloy. Above the eutectic regions (designated as Zone I), an outer mixed Ni/Al-oxide and an inner thin alumina sub-scale formed. Above the dendrite (Zone II) with a lower overall Al-content, internal Al-oxidation prevailed beneath a chromia base scale (Fig. 11). Between the external chromia scale and the internal oxidation zone, a twophase region was present, consisting of $\mathrm{Cr} / \mathrm{Al}$ depleted $\gamma$-matrix and mixed oxide precipitates rich in $\mathrm{Ta}, \mathrm{Ti}$, and $\mathrm{Cr}$ (Fig. 12). The formation of this type of Ta-rich oxide is in qualitative agreement with the results from Jalowicka et al. [26], showing formation of oxides of the type $\mathrm{TaTiO}_{4}$ in the scales grown on the Tacontaining Ni-base superalloy PWA1483, and formation of $\mathrm{TaCrO}_{4}$ in case of the model alloy Ni-14Cr-9Co-3Al-5Ta (composition in mass\%) [26]. The location of Ta-rich oxides is in agreement with the fact that the dissociation pressure of $\mathrm{Ta}_{2} \mathrm{O}_{5}$ lies between those of chromia and alumina if unit activities for all metallic elements are assumed (Table 3). However, when considering metal activities in the alloy using ThermoCalc, pure $\mathrm{Ta}_{2} \mathrm{O}_{5}$ has a thermodynamic stability which is slightly lower than that of $\mathrm{Cr}_{2} \mathrm{O}_{3}$ (Table 3). The reason for this apparent discrepancy might be related to incorrect values of the calculated metal activities, unknown data for the thermodynamic stability of the mixed Ta-containing oxides and/or substantially changed 


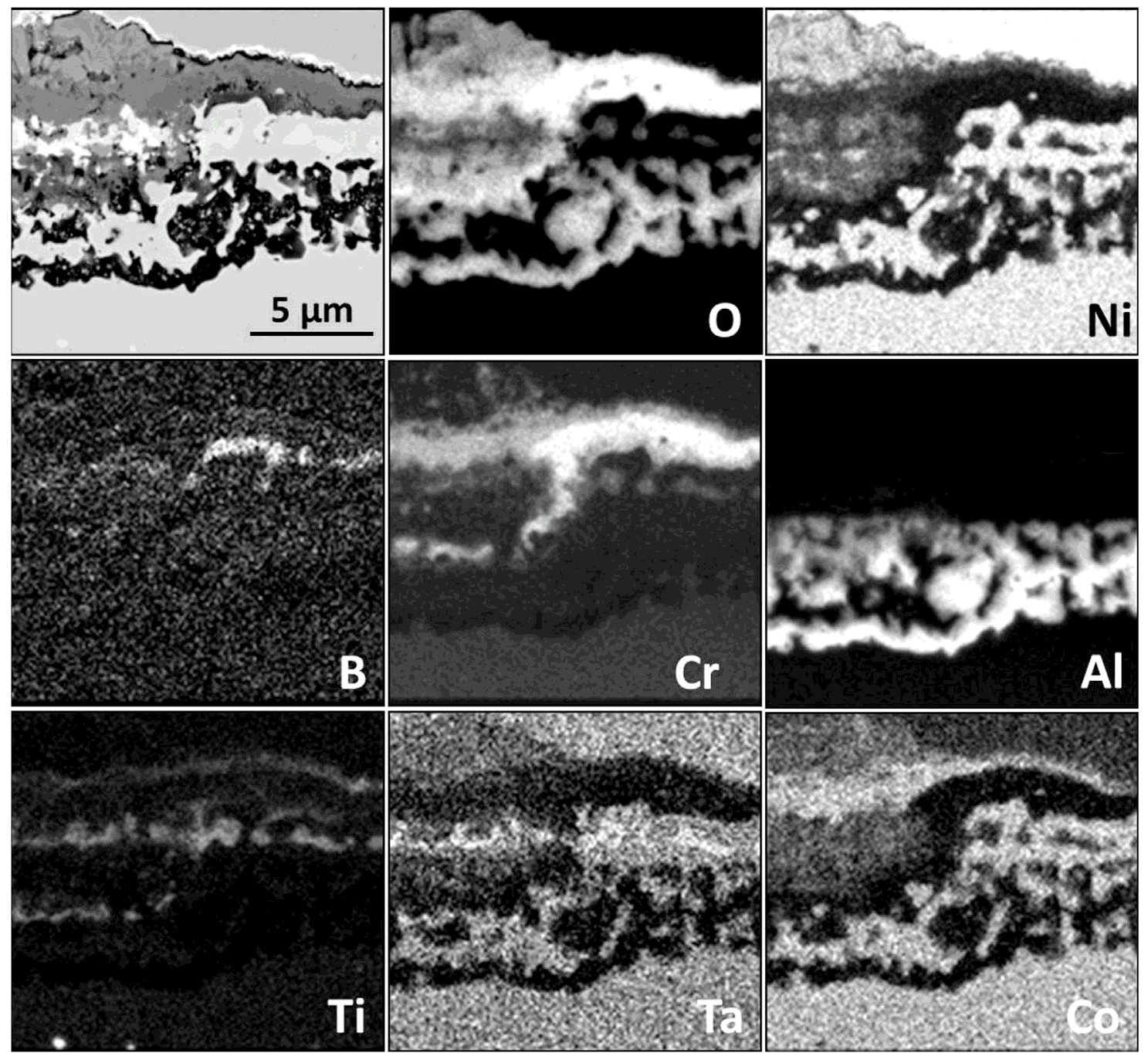

Figure 16. SEM back scattered electron image and corresponding EDX elemental maps for cross-section in Zone II of CM 247 exposed at $1050{ }^{\circ} \mathrm{C}$ for $5 \mathrm{~h}$ in laboratory air (B measured by WDX)

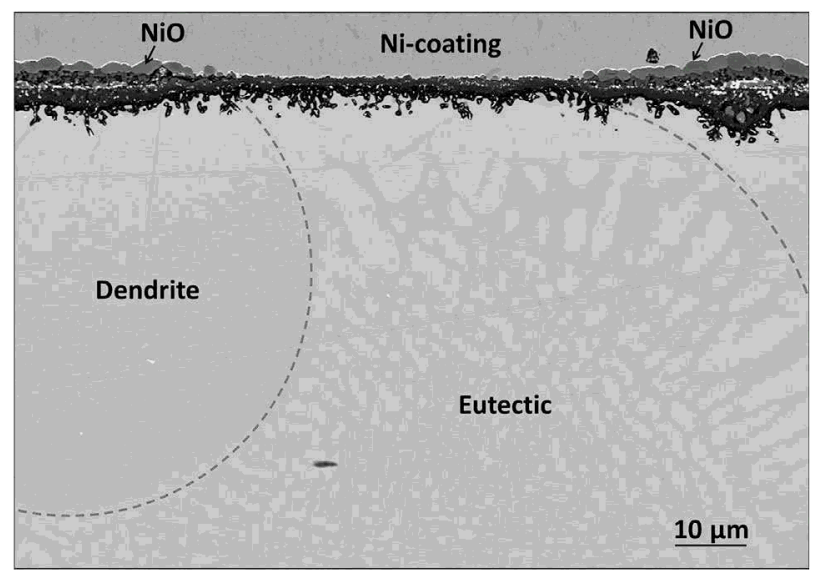

Figure 17. SEM image of the cross section of CM 247 after exposure at $1050^{\circ} \mathrm{C}$ in laboratory air for $50 \mathrm{~h}$ showing the oxide scale morphologies formed above the dendrite (Zone II) and eutectic (Zone I) regions. Dashed lines visualize boundaries between different regions

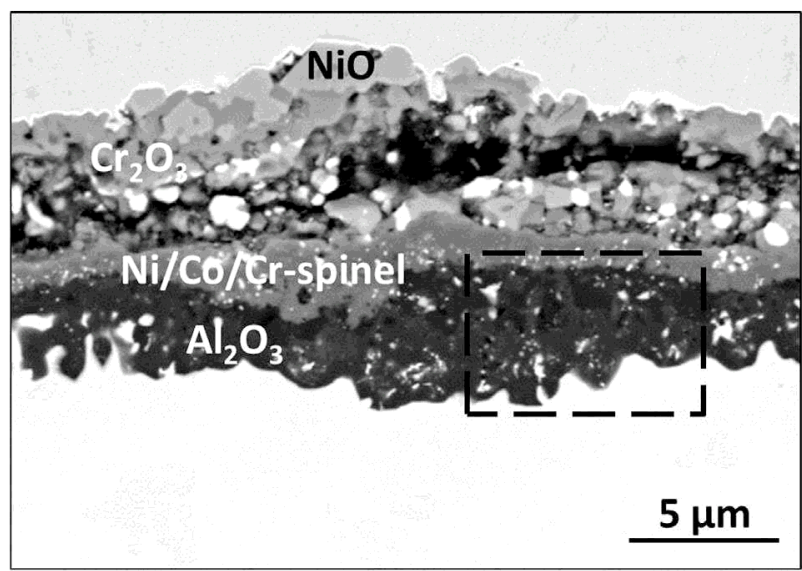

Figure 18. SEM/BSE images showing cross section in Zone II of CM 247 after exposure at $1050^{\circ} \mathrm{C}$ in laboratory air for $100 \mathrm{~h}$. Boxed area shown in more detail in Fig. 19 

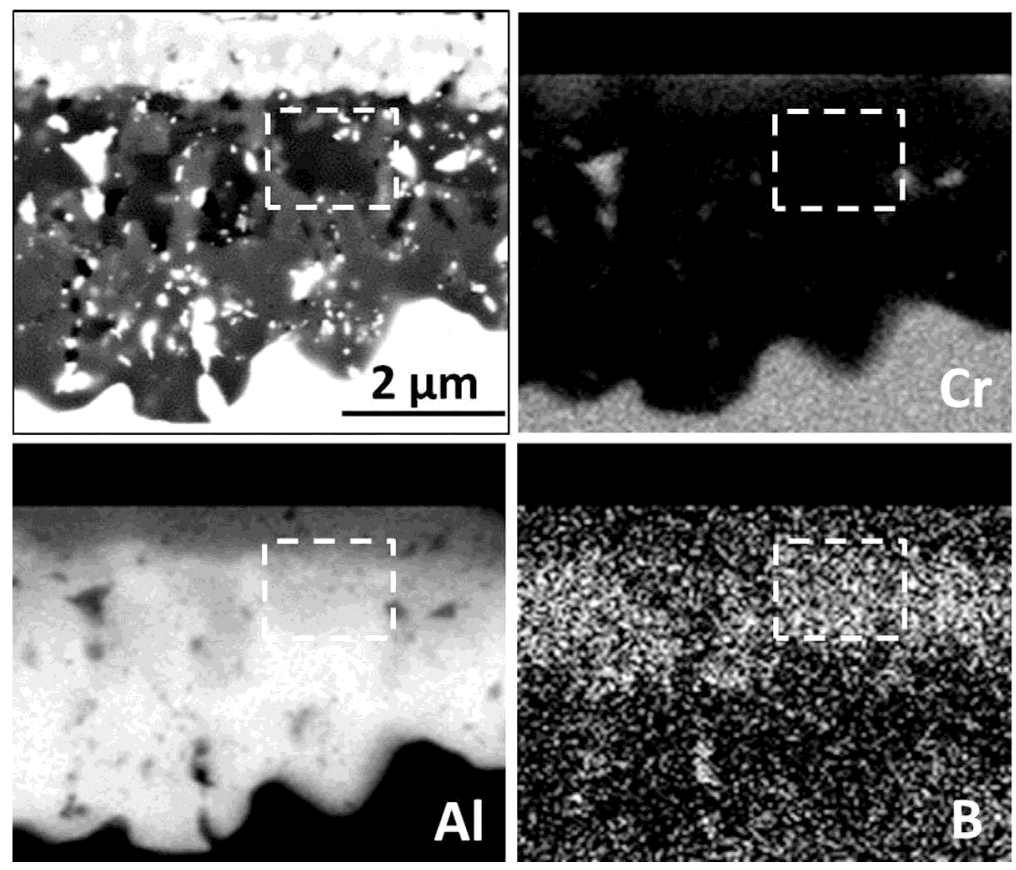

Figure 19. SEM back scattered electron image (upper left) and corresponding EDX elemental maps of boxed area in Fig. 18. The dashed boxes indicate the same place in the cross-section

metal activities (due to depletion processes) in the near-surface regions compared to the values in the bulk alloy.

After exposure for $5 \mathrm{~h}$ at $1050^{\circ} \mathrm{C}$ the two types of scale morphologies found after $1 \mathrm{~h}$ oxidation in Zone I and II could still be identified. In the areas where an inner dense alumina scale had been found already after $1 \mathrm{~h}$ (Zone I, Fig. 10), formation of coarse hafnia pegs was observed (Fig. 14). This is related to internal oxidation of Hf which is possible beneath the dense, inner alumina scale because of the higher thermodynamic stability of hafnia compared to that of alumina (Table 3). Internal

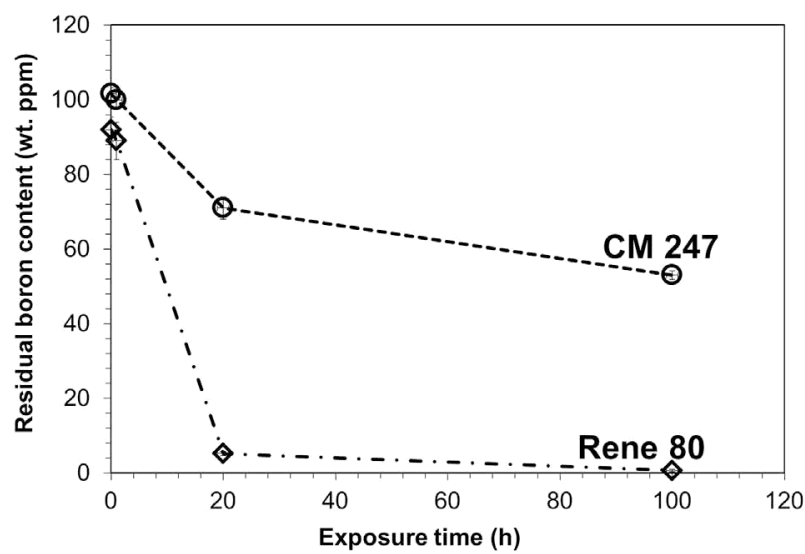

Figure 20. Residual boron content remaining in bulk alloys Rene 80 and $\mathrm{CM} 247$ (2 mm thick coupons) after different oxidation times at $1050{ }^{\circ} \mathrm{C}$ in air (measured by ICP-MS after removal of the oxide scale by grinding). Data for Rene 80 were taken from Ref. [5] oxidation of $\mathrm{Hf}$ is obviously also possible in areas forming an external chromia scale with internal alumina precipitates (Zone II in Fig. 10). In these areas the oxygen activity at the scale/alloy interface is governed by the dissociation pressure of chromia which is substantially higher than that of alumina (Table 3). Based on classical oxidation theory [27] the depth up to which Hf can become internally oxidized is substantially larger than beneath the alumina scale formed in zone I. Therefore the internal hafnia formed in Zone II is expected to appear up to substantially larger depth in form of much finer, discrete

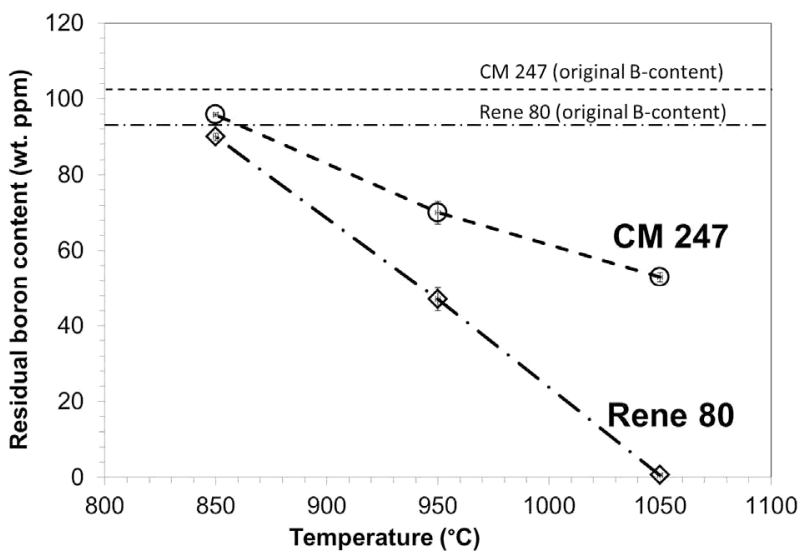

Figure 21. Residual boron content measured by ICP-MS in Rene 80 and CM 247 ( $2 \mathrm{~mm}$ thick coupons) after oxidation for $100 \mathrm{~h}$ in air at different temperatures (measured after removal of the oxide scale). Data for Rene 80 were taken from Ref. [5] 


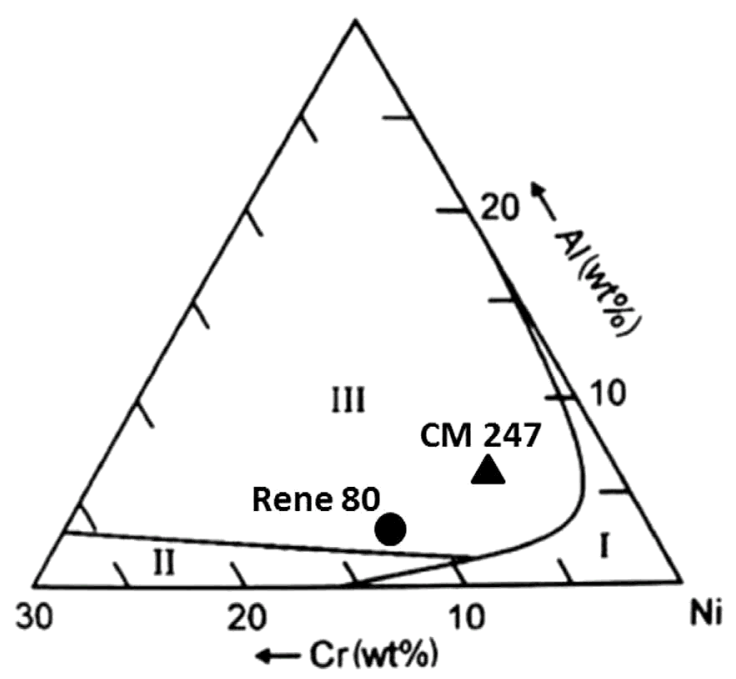

Figure 22. Oxidation map for $\mathrm{Ni}-\mathrm{Cr}-\mathrm{Al}$ alloys [25] showing fields of various types of oxide scale formation as function of alloy $\mathrm{Cr}$ and $\mathrm{Al}-$ contents at $1000-1100{ }^{\circ} \mathrm{C}$ : I-NiO forming alloys, $\mathrm{II}-\mathrm{Cr}_{2} \mathrm{O}_{3}$ forming alloys, III-Al $\mathrm{O}_{3}$ forming alloys. Superimposed are $\mathrm{Cr}$ and $\mathrm{Al}$ contents of Rene 80 and $\mathrm{CM} 247$

precipitates than in Zone I. In the latter area, the internal hafnia precipitates become gradually embedded into the inwardly growing alumina scale resulting in the morphology seen for example, in Fig. 12. A further explanation for the differences in amount and morphology of the $\mathrm{HfO}_{2}$ precipitates in the alumina scale formed in zone I and II after longer exposure times may be related to differences in overall $\mathrm{Hf}$ content in dendrite and eutectic regions. Based on Fig. 4 the average Hf content in the eutectic regions seems to be higher than in the dendrite regions.

After $5 \mathrm{~h}$ exposure, the internal alumina precipitates formed in Zone II started to merge into a continuous sub-scale (Figs. 15 and 16), i.e., a transition from classical internal precipitation to growth of a continuous oxide layer occurred [28]. The increase in the specimen surface area fraction forming a continuous alumina scale is correlated with a substantial drop of the instantaneous $\mathrm{k}_{\mathrm{w}}^{\prime}$ (Fig. 5). A consequence of the connection of internal precipitates of alumina resulting in scale formation is

Table 3. Dissociation pressures at $1050{ }^{\circ} \mathrm{C}$ for various oxides calculated using Factsage, where $\mathrm{pO}_{2}{ }^{*}$ is the dissociation pressure calculated assuming unit activities for the respective oxides and metals

\begin{tabular}{lccc}
\hline Oxide & $\mathrm{pO}_{2}{ }^{*}$, atm & $a_{\mathrm{M}}$ (ThermoCalc) & $\mathrm{pO}_{2}{ }^{* *}$, atm \\
\hline $\mathrm{NiO}$ & $2.3 \cdot 10^{-10}$ & $3.6 \cdot 10^{-1}$ & $1.8 \cdot 10^{-9}$ \\
$\mathrm{Cr}_{2} \mathrm{O}_{3}$ & $2.0 \cdot 10^{-21}$ & $3.4 \cdot 10^{-1}$ & $8.6 \cdot 10^{-21}$ \\
$\mathrm{Ta}_{2} \mathrm{O}_{5}$ & $5.6 \cdot 10^{-24}$ & $8.2 \cdot 10^{-5}$ & $1.1 \cdot 10^{-20}$ \\
$\mathrm{~B}_{2} \mathrm{O}_{3}$ & $1.2 \cdot 10^{-25}$ & $2.7 \cdot 10^{-5}$ & $1.5 \cdot 10^{-19}$ \\
$\mathrm{Al}_{2} \mathrm{O}_{3}$ & $1.0 \cdot 10^{-33}$ & $2.6 \cdot 10^{-5}$ & $1.3 \cdot 10^{-27}$ \\
$\mathrm{HfO}_{2}$ & $3.2 \cdot 10^{-35}$ & $3.2 \cdot 10^{-6}$ & $1.0 \cdot 10^{-29}$ \\
$\mathrm{TiO}$ & $1.2 \cdot 10^{-33}$ & $1.3 \cdot 10^{-5}$ & $6.9 \cdot 10^{-24}$ \\
\hline
\end{tabular}

$\mathrm{pO}_{2}{ }^{* *}$ is the dissociation pressure calculated based on the activity of the elements in CM $247\left(a_{M}\right)$ calculated in ThermoCalc using the data measured by ICP-OES (Table 1). that the alloy regions above the newly formed scale become separated from the bulk alloy. Consequently, the remaining $\mathrm{Cr}$ is rapidly depleted from the isolated alloy regions due to continuing chromia formation. This eventually results in the local oxidation of $\mathrm{Ni}$ and $\mathrm{Co}$ (Fig. 16). Subsequently, the initially present chromia scale becomes unstable. Its reaction with the $\mathrm{Ni}$ - and Co-oxides, eventually leads to formation of mixed $\mathrm{Cr} / \mathrm{Ni} / \mathrm{Co}$ containing oxides, probably of the spinel type (compare the respective EDXmaps at the left hand side of Fig. 16). After prolonged exposure, the growth of NiO-islands on top of this mixed oxide can be observed (Figs. 15 and 16). This reflects outward diffusion of Ni, and to a lesser extent $\mathrm{Co}$, because of the existing oxygen activity gradient in the mixed oxide scale.

After $20 \mathrm{~h}$ oxidation at $1050{ }^{\circ} \mathrm{C}$, a continuous alumina subscale can be found on virtually the whole specimen surface, and the overall oxidation rate is controlled by transport processes in the alumina scale (Fig. 5). The instantaneous value for $\mathrm{k}_{\mathrm{w}}$ at $20 \mathrm{~h}$ (Fig. 5) measured by thermogravimetry is higher than that observed on alumina forming materials such as Ni-aluminides or the alumina forming wrought nickel base alloy 214 [29]. This might be related to the presence of precipitates of various other oxides in the alumina scale (Fig. 18) which provide short circuit paths for oxygen inward diffusion resulting in enhanced inward scale growth and thus increased oxygen uptake.

\subsection{Boron oxidation and depletion}

Analysis by GD-OES and SEM/WDX clearly showed boron oxidation in both studied alloys. In Rene 80 , precipitates of $\mathrm{BCrO}_{3}$ could be found after oxidation at $1050{ }^{\circ} \mathrm{C}$ during exposure times of $1-100 \mathrm{~h}$ in the inner part of the chromia scale [19]. In the case of CM 247, the presence of this compound was identified (in Zone II) as long as an external chromia scale was present (left side of Fig. 15). After an inner, dense alumina scale had formed, no B/Cr-mixed oxide was found near the interface with the alloy (right side of Fig. 15).

When considering pure elements the dissociation pressure of boria in equilibrium with boron at $1050{ }^{\circ} \mathrm{C}$ is three orders of magnitude lower than that of chromia $\left(\mathrm{pO}_{2}{ }^{*}\right.$ in Table 3$)$. In the alloy, however, metal activities are generally lower than unity, resulting in higher dissociation pressures of the respective oxides $\left(\mathrm{pO}_{2}{ }^{* *}\right.$ in Table 3$)$. Based on a comparison of $\mathrm{pO}_{2}{ }^{* *}$ values for the oxides of interest, boron should not be expected to be oxidized underneath the chromia scale. One should, however, keep in mind that the calculation of metal activities in Table 3 does not consider near-surface depletion effects of $\mathrm{Cr}, \mathrm{Al}$, Ta, Ti due to formation of the scale and internal precipitates, which have an effect on both boron and chromium activities. Second, a possibility exists that in the estimation of the boron activity the stability of the boron-rich phases, such as borides are overestimated by ThermoCalc. Indications for such a possibility were found in microstructural studies of a boron containing version of the wrought nickel base alloy IN 617 [2]. In the latter work, no boride precipitates were found by SEM and TEM analyses; rather boron enrichment within and/or at the surface of the $\mathrm{M}_{23} \mathrm{C}_{6}$ type carbide precipitates was detected.

Finally, it is noted that the boron containing oxides observed in the present study are mixed oxides containing $\mathrm{Cr}$ or $\mathrm{Al}$, for 
which no thermodynamic data could be found in the thermodynamic databases available to the authors. It is concluded from the formation of these mixed oxides that they are stable with respect to boria at the prevailing boron activity, and are thus formed at lower oxygen potentials.

Under conditions where boron rich oxides may form, their continuing growth can be explained by the rapid diffusion of boron in the alloy as an interstitial specie (Table 4). At $1050{ }^{\circ} \mathrm{C}$ the boron diffusivity is 3-4 orders of magnitude faster than those of the major alloying additions $\mathrm{Ni}, \mathrm{Cr}$, and $\mathrm{Al}[12,30]$. The continuing oxidation of boron results in the lowering of its concentration in the bulk alloy which, according to the ICP-MS measurements, drops in Rene 80 from 100 to about 5 ppm within just $20 \mathrm{~h}$ oxidation at $1050{ }^{\circ} \mathrm{C}$. After $100 \mathrm{~h}$ exposure at $1050^{\circ} \mathrm{C}$ the boron reservoir within the $2 \mathrm{~mm}$ thick sample of Rene 80 is virtually completely exhausted (Fig. 20).

Boron incorporation into the oxide scale formed on CM 247 in Zone II is initially similar to that found for Rene 80 . After only $1 \mathrm{~h}$ exposure at $1050^{\circ} \mathrm{C}$, the boron rich oxide $\mathrm{BCrO}_{3}$ could be observed in the inner part of the chromia scale. Unlike Rene 80 , alloy CM 247 starts forming a continuous alumina sub-scale between 5 and $20 \mathrm{~h}$ (depending on the underlying alloy microstructure) during air oxidation at $1050^{\circ} \mathrm{C}$. In areas designated as Zone I, formation of the inner alumina scale had commenced after very short exposure times. In such regions, no indication of $\mathrm{BCrO}_{3}$ formation could be found. This finding suggests that the rapid formation of the alumina sub-layer suppresses boron oxidation.

Measurements by ICP-MS (Fig. 20) show that boron depletion in case of CM 247 is far less significant than that observed for Rene 80 . This is attributed to the fact that CM 247 after prolonged exposure forms a dense inner alumina sub-scale, the time at which this effect occurs being different for Zone I and Zone II. The dissociation pressure of alumina in equilibrium with the $\mathrm{Al}$ at the activity prevailing in the bulk alloy (Table 3), is so low as to prevent boron oxidation. It is concluded therefore that boron oxidation occurs only in the transient stages of CM247 oxidation in Zone II, i.e., prior to formation of the continuous alumina scale. The boron-containing mixed oxides found in the alumina scale near its interface with the external scale after longer exposure time (Figs. 18 and 19) therefore probably originate from the earlier stages of oxidation, i.e., before the inner, dense alumina layer was formed. The ICP-MS data in Fig. 20 support this argument, showing that the boron depletion rate between 0 and $20 \mathrm{~h}$ is much greater than that between 20 and $100 \mathrm{~h}$ for CM247.

Table 4. Solute diffusion for $\mathrm{Ni}, \mathrm{Cr}, \mathrm{Al}$ [30], and $\mathrm{B}$ [12] in $\mathrm{Ni}\left(\mathrm{D}_{0}\right.$ is the preexponential term, $Q$ the activation energy, and $D$ the diffusion coefficient at $1050^{\circ} \mathrm{C}$ )

\begin{tabular}{lccc}
\hline & $\mathrm{D}_{0}\left(\mathrm{~m}^{2} / \mathrm{s}\right)$ & $\mathrm{Q}(\mathrm{kJ} / \mathrm{mole})$ & $\mathrm{D}\left(\right.$ at $\left.1050^{\circ} \mathrm{C}\right)$ \\
\hline $\mathrm{Ni}$ & $1.7 \cdot 10^{-4}$ & 285 & $9.41 \cdot 10^{-16}$ \\
$\mathrm{Cr}$ & $1.1 \cdot 10^{-4}$ & 274 & $1.73 \cdot 10^{-15}$ \\
$\mathrm{Al}$ & $1.0 \cdot 10^{-4}$ & 260 & $5.42 \cdot 10^{-15}$ \\
$\mathrm{~B}$ & $2.0 \cdot 10^{-7}$ & 106 & $1.29 \cdot 10^{-11}$ \\
\hline
\end{tabular}

\subsection{Boron depletion at lower temperature}

Measurements by ICP-MS of the residual boron content after exposure at lower temperatures $\left(950\right.$ and $850^{\circ} \mathrm{C}$, Fig. 21) revealed that the boron depletion from both studied materials is substantially less than after reaction at $1050{ }^{\circ} \mathrm{C}$. After $100 \mathrm{~h}$ oxidation at $950{ }^{\circ} \mathrm{C}$ the boron reservoir in the $2 \mathrm{~mm}$ thick specimens of Rene 80 was depleted by $50 \%$ and that of CM 247 by $30 \%$. The less extensive boron depletion at lower temperatures might be related to a slower boron diffusion and/or slower growth kinetics of boron containing oxides [5]. Further studies are required to investigate the boron depletion kinetics and mechanisms at low temperatures. After $100 \mathrm{~h}$ exposure at $850{ }^{\circ} \mathrm{C}$ only minor boron depletion could be observed (Fig. 21). As the oxide scales after the exposure times used at $850{ }^{\circ} \mathrm{C}$ are quite thin, an unequivocal detection of boron rich oxides using EDX/ WDX analyses of scale cross sections is not possible. Therefore GD-OES depth profiles were measured from oxidized specimens of both studied alloys, because of the high sensitivity of this analysis method for boron.

Results for Rene 80 were presented in Ref. [5] and those for CM 247 are shown in Fig. 23. After 100 h oxidation, the external scale on CM 247 is rich in $\mathrm{Cr}$ whereas Al is likely present as internal oxide precipitates in the subsurface zone (see plateau of oxygen profile beneath the external oxide scale in Fig. 23). Boron enrichment in the oxide scale can be clearly seen in the GD-OES profile. Although the boron enrichment at $850{ }^{\circ} \mathrm{C}$ differs quantitatively from that during oxidation at $1050{ }^{\circ} \mathrm{C}$, the
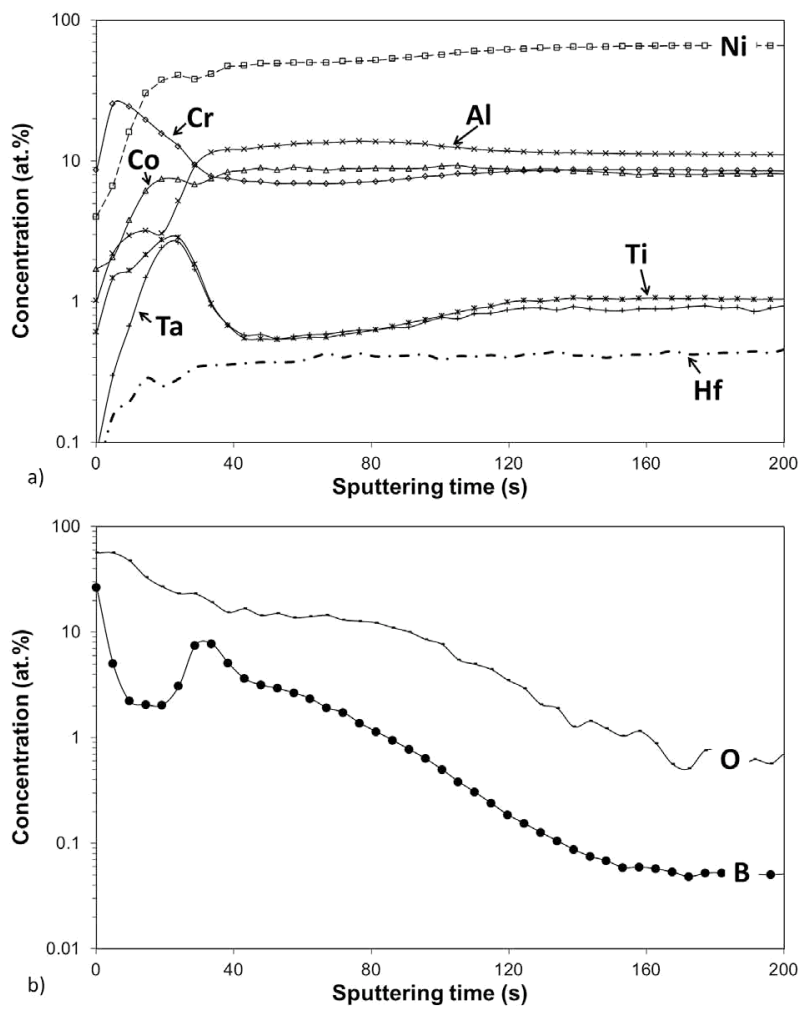

Figure 23. CD-OES depth profiles of $\mathrm{CM} 247$ after oxidation at $850^{\circ} \mathrm{C}$ in laboratory air for $100 \mathrm{~h}$ showing the depth profiles of: a) metallic elements and b) selected non-metallic elements 
qualitative similarity of the GD-OES profiles in Fig. 23 and 13 indicates that formation of the scale and its incorporation of boron are not fundamentally different from that at $1050^{\circ} \mathrm{C}$. Therefore it can be concluded that oxidation induced boron depletion may become important in practical applications of $\mathrm{Ni}$ base superalloys even in the temperature range $800-900{ }^{\circ} \mathrm{C}$, given the lifetimes required for stationary gas turbine components, which are typically $25,000 \mathrm{~h}$ or longer.

\section{Summary and conclusions}

During oxidation at $1050{ }^{\circ} \mathrm{C}$ in laboratory air, Rene 80 formed laterally uniform, chromia-based surface scales, containing $\mathrm{TiO}_{2}$ precipitates in their outer part and $\mathrm{CrTi}_{2} \mathrm{O}_{5}$ and $\mathrm{BCrO}_{3}$ precipitates in their inner part. However, Al was oxidized internally.

Scale formation on CM 247 at $1050{ }^{\circ} \mathrm{C}$ was initially $(1 \mathrm{~h}$ exposure) strongly affected by the alloy microstructure. Above eutectic regions (designated as Zone I), $\mathrm{Ni} / \mathrm{Al}$-spinel along with a $\mathrm{Al}_{2} \mathrm{O}_{3}$ sub-scale formed, whereas an external $\mathrm{Cr}_{2} \mathrm{O}_{3}$-scale with internal $\mathrm{Al}_{2} \mathrm{O}_{3}$ precipitates formed over dendritic regions (Zone II). In the latter regions $\mathrm{BCrO}_{3}$ formed in the inner part of the chromia base scale, whereas GD-OES analyses revealed boron to be enriched in the internal oxidation zone, although to a far lesser extent than in the inner chromia scale region. Between the external chromia scale and the internal oxidation zone was a region consisting of $\mathrm{Cr} / \mathrm{Al}$ depleted alloy matrix and $\mathrm{Ta}(\mathrm{Ti}, \mathrm{Cr}) \mathrm{O}_{4^{-}}$ precipitates. After longer exposure times $(>20 \mathrm{~h})$, an alumina sub-scale also formed on the dendritic alloy regions (Zone II). The inner scale region became more uniform, consisting of alumina containing different types of small oxide precipitates. A mixed Al/B oxide was present in the alumina layer near its interface with an outer $\mathrm{Ni} / \mathrm{Cr} / \mathrm{Co}$ oxide scale layer.

For both superalloys, the formation of boron rich oxides in the surface regions resulted in boron depletion from the bulk alloy. The rate and extent of depletion were much more significant for Rene 80 than for CM 247. This was related to the differences in oxide scale compositions developed by the alloys. In the chromia forming Rene 80, boron became completely depleted within less than $100 \mathrm{~h}$ air exposure at $1050^{\circ} \mathrm{C}$. In CM 247, however, boron depletion occurred only during the transient oxidation stage, i.e., before a dense inner alumina layer had been formed. After formation of the alumina sub-scale the oxygen activity at the scale/alloy interface apparently becomes too low for boron to be oxidized.

Preliminary studies at lower temperatures indicated that boron incorporation into the scale occurred even at $850{ }^{\circ} \mathrm{C}$. Thus, in light of typical operation times $(>25,000 \mathrm{~h})$ of gas turbine components, oxidation induced boron depletion may also be an issue at lower, service relevant temperatures.

Acknowledgments: H. Lippert from the Central Institute for Engineering, Electronics and Analytics, ZEA-3, Forschungszentrum Jülich $\mathrm{GmbH}$ is greatly acknowledged for ICP-OES analyses. The authors are grateful to the following colleagues in the Institute for Energy and Climate Research of the Forschungszentrum Jülich $\mathrm{GmbH}$ for assistance in the experimental work: $H$. Cosler and R. Mahnke for the oxidation experiments, V. Gutzeit and J. Bartsch for metallographic studies, M. Ziegner for XRD analyses, and Dr. E. Wessel and D. Grïner for SEM investigations.

\section{References}

[1] M. J. Donachie, S. J. Donachie, Superallops A Technical Guide, ASM International, Materials Park, USA 2002, p. 37, 235-238.

[2] D. Tytko, P. Choi, J. Klöwer, A. Kostka, G. Inden, D. Raabe, Acta Mater. 2012, 60, 1731.

[3] D. Blavette, P. Duval, L. Letellier, M. Guttmann, Acta Mater. 1996, 44, 4995.

[4] R. Reed, The Superallops Fundamentals and Applications, Cambridge University Press, New York 2006, p. 54, 127, 252-254.

[5] A. Jalowicka, W. Nowak, D. J. Young, V. Nischwitz, D. Naumenko, W. J. Quadakkers, Oxid. Met. 2015, 83, 393.

[6] F. Abe, T. Horiuchi, M. Taneike, K. Sawada, Mater. Sci. Eng. A 2004, 378, 299.

[7] C. A. Barrett, R. Miner, D. Hull, Oxid. Met. 1983, 20, 255.

[8] A. Khanna, W. Quadakkers, P. Kofstad, C. Wasserfuhr, in: 9th EUROCORR, 2-6 Oct, Proc., II, EG-007, Utrecht, NL 1989.

[9] E. Crombie, Method of Selective Grain Growth in Nickel Base Superalloy by Controlled Boron Diffusion. USA/ Pittsburgh Pat 4,401,480, 30 Aug. 1983.

[10] Metals Handbook, Heat Treating, Cleaning, and Finishing, Taylor Lyman, Editor, Eighth Edition, Volume 2, Heat Treating of Heat Resisting Alloys, American Society for Metals, Metals Park, Ohio 1964, pp. 257-268.

[11] Y. Chu, P. Ji, J. Ke, Acta Metall. Sinica 1991, 27, 303.

[12] L. Karlsson, H. Norden, Le J. de Physique Colloques 1986, 47.

[13] D. K. Das, V. Singh, S. V. Joshi, Mater. Sci. Technol. 2003, 19 , 695.

[14] L. Niewolak, M. Malessa, S. Y. Coleman, W. J. Quadakkers, M. Schütze, Mater. Corros. 2006, 57, 5.

[15] W. J. Quadakkers, A. Elschner, W. Speier, H. Nickel, Appl. Surf. Sci. 1991, 52, 271.

[16] H-E. Huang, C-H. Koo, Mater. Trans. Jpn. Inst. Met. 2004, 45, 562.

[17] D. Monceau, B. Pieraggi, Oxid. Met. 1998, 50, 477.

[18] W. J. Quadakkers, D. Naumenko, E. Wessel, V. Kochubey, L. Singheiser, Oxid. Met. 2004, 61, 17.

[19] A. Jalowicka, PhD Thesis, RWTH Aachen University, Aachen, Germany 2013.

[20] M. Schiek, L. Niewolak, W. Nowak, G. H. Meier, R. Vaßen, W. J. Quadakkers, Oxid. Met. 2015, 84, 661.

[21] J. J. Capponi, J. Chenavas, J. C. Joubert, Bulletin de la Société Française Minéralogie et de Cristallographie 1972, 95, 412.

[22] M. Fisch, T. Armbruster, D. Rentsch, E. Libowitzky, T. Pettke, J. Solid State Chem. 2011, 70, 184.

[23] D. Mazza, M. Vallino, G. Busca, J. Am. Ceram. Soc. 1992, 75, 1929.

[24] H. Scholze, Zeitschrift für anorganische und allgemeine Chemie. 1956, 284, 272.

[25] C. S. Giggins, F. S. Pettit, Trans. Metall. Soc. AIME 1968, 245, 2495.

[26] A. Jalowicka, W. Nowak, D. Naumenko, L. Singheiser, W. J. Quadakkers, Mater. Corros. 2014, 65, 178. 
[27] N. Birks, G. H. Meier, F. S. Pettit, High-Temperature Oxidation of Metals, 2nd Edn., Cambridge Univeristy Press, Cambridge, England 2006.

[28] C. Wagner, Zeitschrift für Elektrochemie 1959, 63, 772.

[29] A. Chyrkin, N. Mortazavi, M. Halvarsson, D. Grüner, W. J. Quadakkers, Corros. Sci. 2015, 98, 688.
[30] H. Bakker, H. P. Bonzel, C. M. Bruff, M. A. Dayananda, W. Gust, J. Horváth, I. Kaur, G. V. Kidson, A. D. LeClaire, H. Mehrer, G. E. Murch, G. Neumann, N. Stolica, N. A. Stolwijk, Landolt-Börnstein, New Series HI/26, Springer Verlag, Berlin, Heidelberg 1990.

(Received: January 7, 2016)

W8837 